SERVIÇO DE PÓS-GRADUAÇÃO DO ICMC-USP

Data de Depósito: 01.03.2004

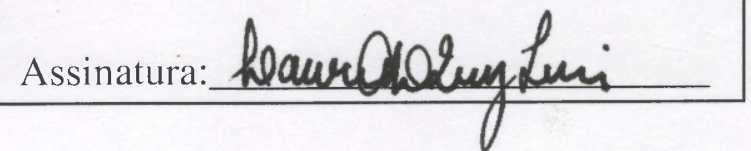

\title{
Anotações com PDAs: extensão da área de escrita e integração com o Projeto InCA-SERVE ${ }^{1}$
}

\author{
Carlos Frederico Penedo Rocha
}

Orientadora: $\operatorname{Prof}^{a}$. Dr ${ }^{a}$. Maria da Graça Campos Pimentel

Dissertação apresentada ao Instituto de Ciências Matemáticas e de Computação - ICMC-USP, como parte dos requisitos para obtenção do título de Mestre em Ciências de Computação e Matemática Computacional.

\author{
USP - São Carlos \\ Março/2004
}




\section{A Comissão Julgadora:}

Profa. Dra. Maria da Graça Campos Pimentel

Prof. Dr. Ethan Munson

Profa. Dra. Heloisa Veira da Rocha
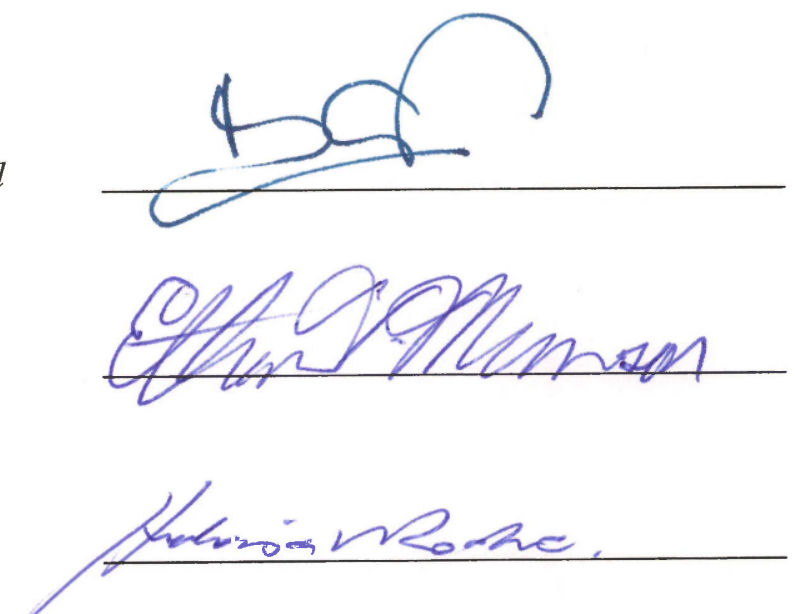


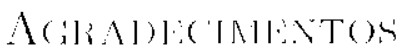

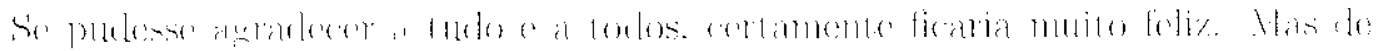

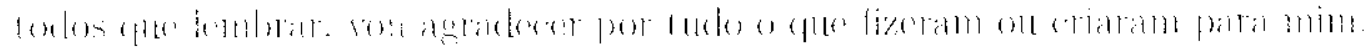

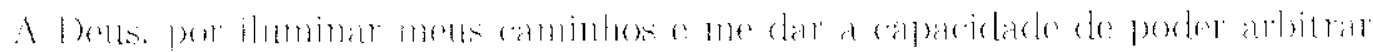

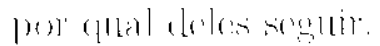

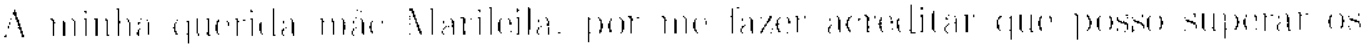

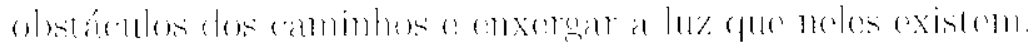

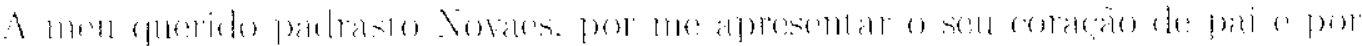

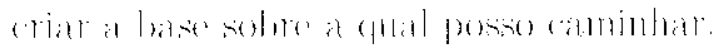

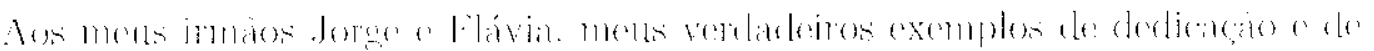

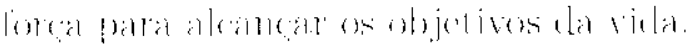

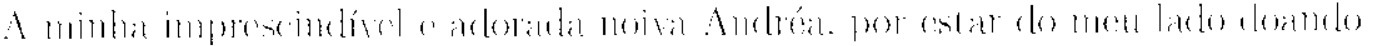

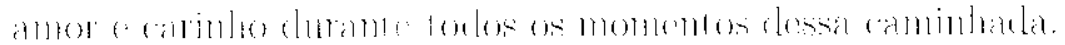

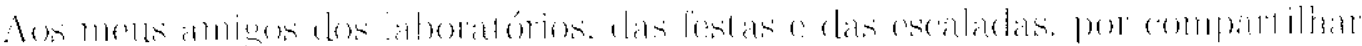

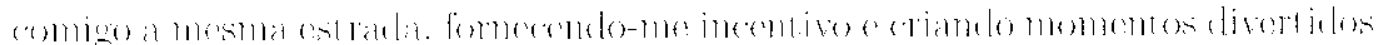
10lives.

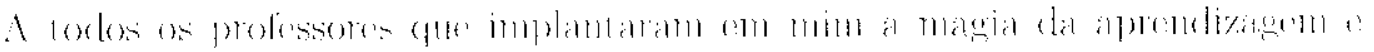

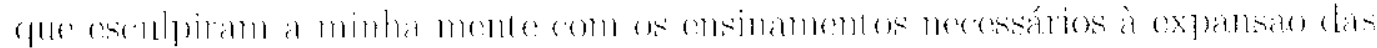

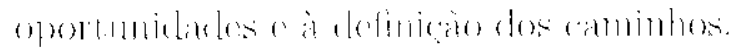

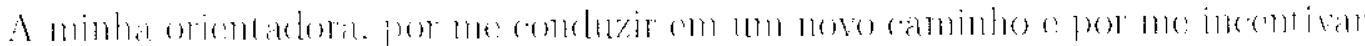

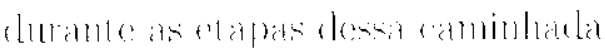

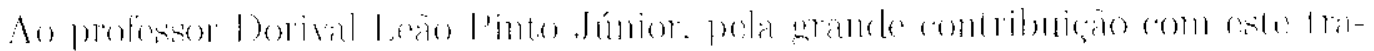
lialhe, 


\section{Resumo}

A computação ubíqua, uma das mais recentes áreas da Ciência da Computação, tem como objetivo tornar os serviços computacionais tão intrínsecos a um determinado ambiente que se tornam transparentes para seus usuários. Este trabalho se insere nesse contexto, tanto buscando apoiar as atividades cotidianas de um usuário em particular quanto provendo flexibilidade de comunicação entre um conjunto de usuários de inodo geral. Investigando os problemas associados, desenvolvemos um sistema de anotações visando a captura e o acesso a informações públicas em experiências ao vivo, tais como aulas prescnciais, utilizando, para tanto, dispositivos pessoais digitais (ou PDAs -- Personal Digital Assistants). Apesar dos PDAs apresentarem vantagens como portabilidade e baixo consumo de cnergia, a limitação de sua tela representa problemas para usuários, que, geralmente, têm dificuldade em visualizar e interagir com uma quantidade de informações que extrapola o tamanho da tela desse dispositivo. Neste trabalho, implementamos um sistema que simula uma área de anotações maior do que a tcla dos PDAs e elaboramos um mecanismo de rolagem de textos para favorecer a escrita de anotações. Para avaliar esse mecanismo e o impacto da utilização de uma área maior na orientação espacial do usuário, conduzimos dois expcrimontos c analisamos seus resultados. Por fim, acoplamos essas características no sistema desenvolvido e o integramos à infra-estrutura do Projeto InCA-SERVE, cm utilização pelo grupo de hipermídia do ICMC-USP. 


\begin{abstract}
One of the most recent areas of Computer Science, ubiquitous computing is concerned with providing computer support invisible for its users. According to this idea, the aim of our work is to support activities from a particular user and provide means of communication among serveral users in a group. Investigating the related problems, we built an annotation system to capture and access public informations on live experiences, such as live classes, using Personal Digital Assistants. The small size of such devices provides the convenience of mobility at the expense of reduced screen space for display and interaction. So, a key limitation of these devices is the user's inability to view and interact with information that occupies an area bigger than the original screen. In our system, we created a virtual area bigger than the PDA screen and provided an automatic scroll mechanism to aid taking annotations. We evaluated this mechanism and the impact of using the virtual area in user's spatial orientation by conducting two experiments and analysing their results. Finally, we integrated the system with the infrastructure of the Projeto InCA-SERVE that is being used by the hypermedia group at IC.MC-USP.
\end{abstract}


Aos meus pais Novaes e Marileila, meus irmãos Jorge e Flávia, meus sobrinhos Ana Clara, Caio e Igor e minha noiva Andréa. 


\section{Lista de Figuras}

2.1 Enhanced Wall: display interativo utilizando mecanismos de rastreamento de faces. . . . . 9

2.2 Ambient Dinplay: tubos com água exibindo a palava "UlST". . . . . . . . . . . . 10

2.3 Esquerda: MediaCup, ilustração de un artefato digital. Direita: MonoClip, um grampo preso à roupa que procura por informaçoss de localizacáo do nsuário. . . . . . . . . . . 11

2.4 Aware flome: residência utilizada cono laboratório para pesquisas de computaçăo ubíqua. 12

2.5 Family Intercom: porta-retrato utilizado para comunicação entre famílias cun casas distintas. 13

2.6 Sala de aulit instrumentada. . . . . . . . . . . . . . . . . . . . . . . 14

2.7 O sistena StuPad nsado em sala de anla. . . . . . . . . . . . . . . . . . . . . . . . 15

2.8 Comunicacás entre os componentes xINCA de whiteboard e chat. . . . . . . . . . . . 19

2.9 Captura de mata aula pelo Sistenta iClass. . . . . . . . . . . . . . . . . . . . . . . . 20

3.1 Esquerda: interface utilizada no experimento. Direita: ilustração da janela de anotação e da źrea virtual. . . . . . . . . . . . . . . . . . . . . .

3.2 Tarefa A: treinamento do usuário. Esquerda: configuaça inicial da tarefa. Direita: um usuário percorrendo as linhas unstras. . . . . . . . . . . . . . . . . . . . .

3.3 Tarefa B: solorepor uma curva simples. Esquerła: configuração inicial da tarefa. Direita: um usuário percorrendo a curva. . . . . . . . . . . . . . . . . . . . . . . . . .

3.1 Tarefa C: sobrepor tros curvas existentes. Esquerda: configuragato inicial da harefa. Dincita: um usuário percorrendo o início da segunda curva. . . . . . . . . . . . . . . . . . . . 
3.5 Tarefa D: escrita livre. Esquerda: configuragno inicial da tarefa. Direita: frase escrita por un usuário. . . . . . . . . . . . . . . . . . . . . . . . . . 30

3.6 Esquerda: Tarefa E, de treinamento. Direita: Tarefa G, das tres curvas. . . . . . . . . 30

3.7 Fatores que infuenciam o tempo para se completar a tarefa: tipo de deslocamento. ordem c atividade. . . . . . . . . . . . . . . . . . . . . . . . . . 31

3.8 Fatores que influenciam a variavel resposta distância. . . . . . . . . . . . . . . . . 32

3.9 Escrita live com e sem deslocanento antomático. . . . . . . . . . . . . . . . . . 33

3.10 Esquerda: configuraço inicial do relógio para cada tarefa. Dircita: desento das matcacoos do relógio. . . . . . . . . . . . . . . . . . . . .

3.11 Interface utilizada no experimonto, com um botão para deslocamonto manual (A), para desonks $(\mathrm{B})$ o borracha $(\mathrm{C})$. . . . . . . . . . . . . . . . . . . . 36

3.12 Threfas executadas por um usuário: 3 h, 8:40h, 2:45h e 11:10h. . . . . . . . . . . . . 37

3.13 Aplicaçà de um gabarito sobre os relógios da figura anterior. . . . . . . . . . . . . . 37

3.14 Grálico da ordem de execuço da tarofa versus o tempo cm scgundos. . . . . . . . . . . 38

3.15 Gráfico da distância das marcas. con milímetros, sob influĉncia dos horários c so horário correto. . . . . . . . . . . . . . . . . .

3.16 Gráfico do sexo versus a distância do centro, om milinetros. . . . . . . . . . . . .

4.1 Commicaço entre os trôs servicos do Sistema aNOTE: iPocket. iserver e ilublic. . . .

1.2 Telas do iPocket. Esquerda: sclecão do curso a da aula. Centro selega de um slide já existente. Direita: ferranentas cregião de escrita de anotaçon. . . . . . . . . . .

4.3 Telas do illocket. Escuerda: criação do un link para o primeiro slide. Direita: exibição das opcoss de envio da anotacio: por cabo, infravermolho on rede witess. . . . . . . . . .

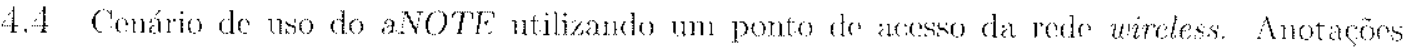

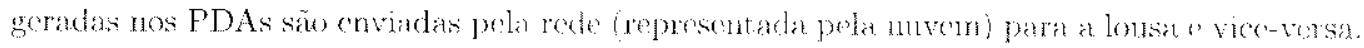




\section{Lista de Tabelas}

3.1 Análise da variância para o tempo. . . . . . . . . . . . . . . . . . 38

3.2 Análise da variância para a distância das marcas. . . . . . . . . . . . . . . . . . . 39

3.3 Análise da variância para a distância das marcas sob influência da relaçāo entre a corretitudo do borário e a ordem em que săo feitos. . . . . . . . . . . . . . . . . 39

3.4 Análise dà variància para a distância do centro. . . . . . . . . . . 40

3.5 Regressáo logística. . . . . . . . . . . . . . . . . . . . . . 41 


\section{Sumário}

1 Introdução 1

1.1 Contextualização . . . . . . . . . . . . . . . . . 1

1.2 Motivação . . . . . . . . . . . . . . . . . . . . . . . 2

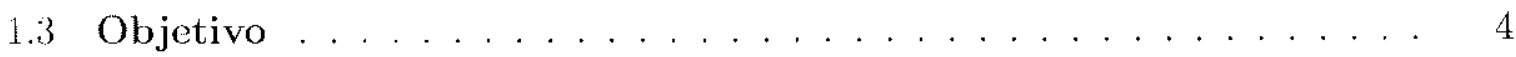

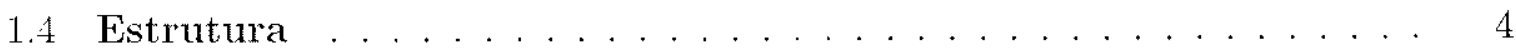

2 Computação Ubíqua $\quad 7$

2.1 Considerações Iniciais . . . . . . . . . . . . . . . . 7

2.2 Interfaces Naturais . . . . . . . . . . . . . . . . . . 8

2.3 Computação Ciente de Contexto . . . . . . . . . . . . 10

2.4 Captura e Acesso a Informações . . . . . . . . . . . . . . . . . 13

2.5 Considerações Finais . . . . . . . . . . . . . . . . 21

3 Anotações com Área de Escrita

Ampliada $\quad 23$

3.1 Consideraçōes Iniciais . . . . . . . . . . . . . . . . . 23

3.2 Mecanismo de Rolagem de Textos em PDAs . . . . . . . . . . 25

3.2 .1 Planejamento . . . . . . . . . . . . . . . 26 
3.2 .2 Execução do Experimento . . . . . . . . . . . . . . . . 28

3.2 .3 Análise dos Resultados . . . . . . . . . . . . . . . . . . 31

3.3 Avaliação da Orientação Espacial . . . . . . . . . . . . . . . . 33

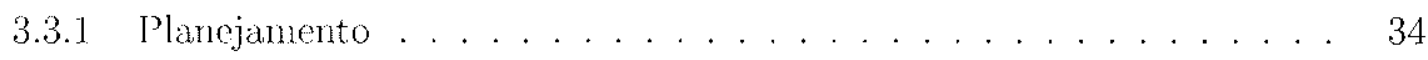

3.3.2 Execução do Experimento . . . . . . . . . . . . . . . 35

3.3.3 Análise dos Resultados . . . . . . . . . . . . . . . . . 36

3.4 Considerações Finais . . . . . . . . . . . . . . . . . . . 41

4 Anotações em PDAs Integradas ao

Projeto InCA-SERVE 43

4.1 Considerações Iniciais . . . . . . . . . . . . . . . . . . . . . 43

4.2 Apresentação do Sistema aNOTE . . . . . . . . . . . . 45

4.3 Armazenamento das Anotações . . . . . . . . . . . . . . . 49

4.3 .1 Armazemanento Privado . . . . . . . . . . . . . . . . 49

4.3 .2 Armazenamento Público . . . . . . . . . . . . . . 51

4.4 Apresentação das Anotações na Web . . . . . . . . . . . 55

4.5 Considerações Finais . . . . . . . . . . . . . . . . . 57

5 Conclusão $\quad 59$

5.1 Considerações Iniciais . . . . . . . . . . . . . . . . . . . . . . . . 59

5.2 Resultados e Contribuições . . . . . . . . . . . . . . 60

5.3 Trabalhos Futuros . . . . . . . . . . . . . . . 61

$\begin{array}{lr}\text { Bibliografia } & 68\end{array}$ 


\section{Capítulo 1}

\section{Introdução}

\subsection{Contextualização}

A computação está cada véz mais presente em atividades cotidianas, seja no trabalho, na área acadêmica on em nossa própria casa. A idéia do termo "computação ubíqua" é que os dispositivos computacionais estejam integrados nesses ambientes de modo transparente, provendo serviços para auxiliar os usuários na realização de suas tarefas. Dessa forma, observamos que a computação assume um comportamento onipresente, estando ao mesmo tempo em toda a parte. Em outras palavras, a computação ubíqua pode ser encarada sob um ponto de vista oposto ao da realidade virtual: enquanto esta introduz as pessoas em um mundo criado por computador, a computação ubíqua força os computadores a se adaptarem ao mundo real [Weiser, 2004].

A computação ubíqua foi concebida em 1988 pelo pesquisador Mark Weiser do Xerox PARC, embora as primeiras publicações na área datem de 1991. Weiser estava interessado em explorar novos paradigmas de interação, tornando os computadores efetivamente invisíveis para o usuário. Esse tema influenciou muitos pesquisadores das ciências de computação no desenvolvimento de trabalhos relacionados a componentes de hardware, protocolos de rede, mecanismos de interação usuário-computador e privacidade. De fato, na última década presenciamos a proliferação de dispositivos computacionais ubíquos de diversos tamanhos: pequenos e pessoais (inch-scale), de médio porte (foot-scale) e grandes e de uso coletivo 
(yardscale). Dispositivos móveis tais como PDAs (Personal Digital Assistants) ${ }^{1}$, tablets digitais e laptops tornaram-se comuns no final da década de 90. Da mesma forma, dispositivos maiores, como lousas eletrônicas, passaram a fazer parte de ambientes de uso comum, tais como salas de reuniões, salas de aula e laboratórios. Além desses, hoje em dia são usados dispositivos que extrapolam as escalas inicialmente previstas por Weiser. São os chamados wall-sized, abrangendo, por exemplo, paredes intciras cujas superfícics são monitoradas por sensores $\left(\right.$ mimios $\left.^{2}\right)$.

Alguns desses dispositivos, como PDAs, lousa cletrônica c mimios, estão sendo explorados pelo Projeto InCA-SERVE. Esse projeto é resultante de uma parceria cntrc o Georgia Institute of Technology (GATECH), sob coordenação do Dr. Gregory Abowd, e o ICMC-LSP, onde é coordenado pela orientadora deste trabalho, com apoio financeiro da Nalional Science Foundalion (NSF), nos EUA, c do CNPq e FAPESP, no Brasil [P'incntel e Abowd, 1999].

O Projeto InCA-SERVE envolve a construção de duas infra-cstruturas: InCA (Infrastructure for Capture and Access) c SERVE (Infrasluclure for Store, Extend, Retrieve and Visualize Evolutionary Information). A primcira provê serviços para captura e accsso às informaçõos associadas a experiências diárias para vários domínios. A segunda está sendo definida bascando-se em um conjunto de aplicações Web independentes e cornplementares, integradas através de APIs. Além disso, essa infra-estrutura está scndo implementada através da construção de serviços Web (Web Services) que suportam atividades de ensino c de reuniōos no Instituto de Ciências Matemáticas c de Computação (ICMC-USP) c no GATECH.

Este trabalho se inscre no contexto do Projeto InCA-SERVE, tanto buscando apoiar as atividades cotidianas de um usuário em particular quanto provendo flexibilidade de comunicação entre um conjunto de usuários de modo geral.

\subsection{Motivação}

Recentemente, temos observado um grande interesse em dispositivos computacionais portáteis como os PDAs e os celularcs. Sua forma reduzida faz com que esses dispositivos tenham

\footnotetext{
${ }^{1}$ Como exemplo, podemos citar os dispositivos portáteis das plataformas Palm e Pocket PC

${ }^{2}$ htt.tp://www.mimio.com
} 
algumas vantagens como portabilidade, baixo consumo de energia e capacidade para serom utilizados cm qualquer lugar, a qualquer momento. No entanto, a limitação da tela representa problemas para usuários, que têm dificuldade em visualizar e interagir com uma quantidade de informações que extrapola o tamanho da tela do dispositivo [Yee, 2003].

Devido às limitações da tela, os PDAs possucm alguns mecanismos de rolagem (scrolling) para prover accsso a informações que não são visíveis inicialmentc. Geralmente, observamos a presença de botões no próprio dispositivo para movimentação vertical, e barras de rolagern em tclas scnsíveis ao toque. Por exemplo, uma técnica padrão para visualização de mapas e fotografias é crmpregar a caneta do dispositivo para arrastar a imagem para a posição desejada. Porém, a tarefa de rolagem pode ser lenta quando a navegação é feita em documentos longos, uma vez que os usuários devem pressionar ou mover um botão várias vezes para cobrir grandes distâncias. Além disso, usar mecanismos de rolagem com barras ou com canetas obriga o usuário a interromper a interação corrente com a caneta e a desviar sua atençâo para as manobras de rolagem.

Não obstante, esses dispositivos têm várias aplicações, incluindo gercnciamento de tarefas de agendamento, armazenamento de dados e acesso e disseminação de informações. Além disso, existem programas que permitem a leitura e a edição de livros eletrônicos (e-books) para a maioria dos dispositivos pessoais. Isso significa que os PDAs também podem ser usados para ler e interagir com textos cletronicos, podendo, inclusive, ser explorados como ferramentas de ensino [Waycott e Kukulska-Hulme, 2003]. Os PDAs podem ser aplicados crn bibliotecas, museus, no trabalho, em salas de aula, ou mesmo dentro de casa.

Contando com a infra-estrutura de hardware e sofitware do Projeto InCA-SERVE, investigamos mecanismos para aplicar os PDAs em ambientes de ensino de modo a fornecer uma ferramenta de anotação que promova a colaboratividade nesses ambientes.

Dadas as limitações de tela inerentes aos dispositivos portátcis, projetamos e implementamos urn sistema que simula uma área de anotações retangular maior do que a tela de $\mathrm{PD} \Lambda$ s. Com isso, surgiu a necessidade de prover um mecanismo efctivo de rolagem de textos durante a realização de anotações nesses dispositivos. Para esse caso, consideramos que a vclocidade de anotação é um fator importante principalmente durante atividades ao vivo, como em urna 
sala de aula, e, portanto, torna-se essencial que anotações sejam fcitas de modo livre.

Na etapa final do desenvolvimento deste trabalho, utilizamos um PDA de última geração, da plataforma PocketPC - iPAQ modelo H5500 [iPAQ, 2003] — que possui um sistema de anotações cujo mecanismo de rolagem aprescnta scmelhanças ao desenvolvido durante estc trabalho. A diferença é que nosso sistema é capaz de simular as dimensões de um caderno convencional e que a rolagem pode ser feita nas direções horizontal e vertical, cnquanto que o iPAQ utiliza apcnas a rolagem na vertical. O PDA em questão foi adqquirido em função do projcto HP (Hewlett-Packard) junto à USP [Masiero et al., 2003].

\subsection{Objetivo}

Para explorar o uso de dispositos computacionais móvcis c ubíquos, surgiram novas aplicações cujo desenvolvimento está associado a três temas que concentram o foco de pesquisa nárea de computação ubíqua: interfaces naturais, captura e acesso a informações capturadas em cxperiências ao vivo e computação ciente de contexto [Abowd c Mynatt, 2000]. Este trabalho abrange os aspectos relacionados aos dois primeiros temas.

Em relação a intcrfaces naturais, o objctivo é avaliar o impacto causado pelo esquema de rolagem utilizado em nosso sistcma, bem como conhecer os aspectos relacionados à localização espacial dos usuários, visto que a área de anotação é maior que a tela do dispositivo.

Em relação ao segundo tema, o objetivo é integrar nosso sistema com a infra-estrutura de captura e acesso do Projeto InCA-SERVE. Com isso, anotações podem ser anexadas aos dados (imagcm, áudio e vídeo) gerados durante uma sessão de captura (aula, reunião on palestra).

\subsection{Estrutura}

Esta dissertação encontra-se organizada da seguinte forma. No Capítulo 2 apresentamos com mais detalhes os temas relacionados à computação ubíqua e as pesquisas existentes na área. No Capítulo 3 abordamos o planejamento, a execução e a análise dos resultados de dois experimentos conduzidos para avaliar tanto o mecanismo desenvolvido para rolagem 
automática de textos durante anotações cm PDAs quanto o impacto causado pela utilização de uma área virtual que extrapola o tamanho da tela desses dispositivos. No Capítulo 4 apresentamos os estudos de integração deste trabalho com o Projeto InCA-SERVE e os aspectos de implementação do sistema de anotações utilizando PDAs. Finalmente, no Capítulo j são tecidas as conclusões finais e apresentados os trabalhos futuros. 


\section{Capítulo 2}

\section{Computação Ubíqua}

\subsection{Considerações Iniciais}

Pesquisas na área de computação ubíqua iniciaram-se cm 1988 no Xerox PARC (Palo Alto Research Center) [Weiser, 1993]. Naquela época, havia interesse na investigação de ambicntes computacionais que seriam utilizados na próxima geração da computação.

A proposta era direcionada à utilização de vários computadores interligados sem fio, com os quais cada pessoa realizaria interações de modo transparente, isto é, a interação deveria acontecer sem a utilização cxplícita de um computador. Com isso, surgiu a necessidade de novos tipos de computadores, de diferentes formas e tamanhos, mas com capacidade e potência razoáveis. Para tais computadores, surgiram novas aplicações e novos paradigmas de interação inspirados pelo amplo e crescente acesso a informações.

$\Lambda$ plicações desse tipo foram agrupadas de acordo com suas características comuns em três temas por [Abowd e Mynatt, 2000], da seguinte forma: interfaces naturais (discutidas na Seção 2.2), computação ciente de contexto (aprescritada na Seção 2.3) e captura c acesso a informações (introduzidas na Seção 2.4). Na Seção 2.5 são apresentadas as considerações finais a respeito desses temas e sua importância no contexto deste trabalho. 


\subsection{Interfaces Naturais}

A computação ubíqua inspira o descnvolvimento de aplicações cujo objetivo é a não utilizaçăo do paradigma convencional (teclado, mouse e display). Dessa forma, csforços são concentrados na construção de aplicações capazes de explorar o modo com que os humanos interagem com o mundo físico. Humanos falam, gesticulam e escrevem para se comunicarcm cntre si. $\Lambda$ ções naturais como essas poderiam ser usadas, explícita ou implicitamente, como entrada para sistemas ubíquos [Abowd e Mynatt, 2000].

Nos últimos anos, surgiram vários sistemas e dispositivos capazes de suportar formas naturais de comunicação (reconhecimento de escrita, voz c gestos). Esses sistemas são caracterizados pela facilidade de aprendizagem e de uso e também são utilizados por pessoas que apresentam dificuldades de manuseio de teclado e mouse. No entanto, ainda são necessários mecanismos robustos para reconhecimento e tratamento de erros relacionados às novas interfaces.

Higel [Higel et al., 2003] propõe a utilização de uma interface unificada para dispositivos com os quais usuários geralmente interagem. O sistema desenvolvido por Higel, denominado TSUNAMI, monitora implicitamente informações de usuários, tais como gestos ou comentários, e as utiliza para predizer que tipo de assistência o usuário requer. Vários tipos de origem produzem dados para esse sistema. Sensores dispersos pelo ambicnte fornecem dados sobre manipulação de objctos, gestos ou vo\%. Calendários agregam informações de tempo. A biografia do usuário auxilia a predição de fatos, bascando-se cm preferências e comportamentos prévios. Lousas eletrônicas e interfaces tradicionais permitem que a entrada de dados seja fcita de mancira não ambígua. Lma vez que a predição esteja formada, una requisição é construída e enviada para um serviço adaptativo, de modo que uma solução possa ser preparada.

Interfaces naturais também podem ser aplicadas na área militar. Flippo [Flippo, 2003] desenvolveu um sistema para controle de véculos robotizados que geralmente são utilizados cm áreas onde há grande incidência de explosivos subtcrâneos. Esses veículos podem ser operados remotamente ou podom trabathar com autonomia. No primeiro caso, a interface de controle do veículo utiliza processamento de linguagem natural e outras modalidades como 
visão e reconhecimento de gestos.

Na tentativa de permitir a manipulação direta de objetos reais e projetados, Nakanishi ct al. [Nakanishi ct al., 2002] desenvolveram o EnhancedDesk, um sistema com características inovadoras, incluindo rastreamento rápido e preciso da posição das mãos e dos dedos, c o cadastramento e reconhecimento de objetos com gestos manuais. O EnhancedWall, outro sistema desenvolvido pelo grupo de pesquisa de Nakanishi, é constituído por mecanismos de rastreamento de faces e por aplicações responsáveis pela interatividade com o usuário (Figura 2.1). Quando projetadas na parede, essas aplicações permitem que o usuário especifique informações de interesse, exibindo determinados itens com maior ou menor detalhamento.

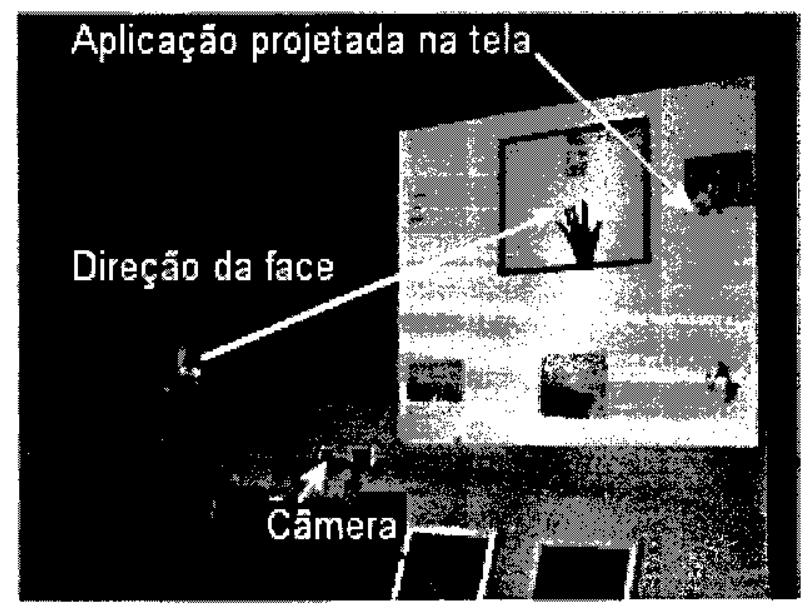

Figura 2.1: EnhancedWall: display interativo utilizando mecanismos de rastrcamento de faces.

A maioria dos projetos requer que o usuário dirija sua atenção para a interface, o que pode compromenter aspectos de usabilidade em ambientes que possuem muitos dispositivos. Os Ambient Displays são exemplos de sistemas que não possuem essa propricuade, ou scja, cles são projetados para conduzir informações que o usuário pode ou não desejar obter em um determinado momento. Ambient Displays se caracterizam por trabalharem na periferia da atenção do usuário, movendo-se para o centro apenas quando apropriado ou desejado.

O Information Percolator [Heiner et al., 1999] é um exemplo de Ambient Display. Tratase de um conjunto de tubos transparentes de água, dentro dos quais são liberadas bolhas de ar em quantidades e cm momentos diferentes, formando imagens que podem ou não conduzir informaçõos relevantes para os usuários (Figura 2.2). Esses objetos podem ser, portanto, considerados instrumentos decorativos, esteticamente interessantes para serem colocados em 
diversos tipos de ambientes.

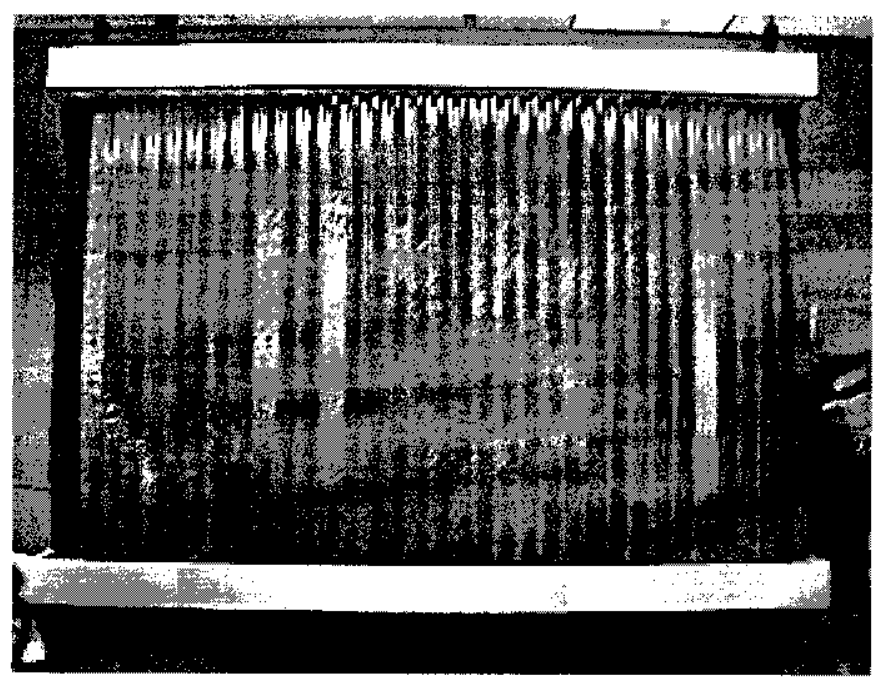

Figura 2.2: AmbientDisplay: tubos com água exibindo a palavra "UIST".

Muitas das abordagens utilizadas em interfaces naturais utilizam informações contextuais. Os trabalhos de Higel c Nakanishi evidenciam esse fato. De um modo geral, os Ambient Displays também são projetados para conduzir informações de contexto para os usuários. Na próxima seção, apresentamos como essas informaçõcs podem influir no comportamento de sistemas de acordo com o conhecimento do ambiente.

\subsection{Computação Ciente de Contexto}

De acordo com Dey [Dcy, 2001], contexto' é qualquer informação que pode ser usada para caractcrizar a situação de uma entidade. Uma entidade pode ser uma pessoa, um lugar, ou um objeto considerados relevantes para a intcração entre o usuário e a aplicação. Um sistema é ciente de contexto se usar contcxto para prover informação ou serviços para um usuário.

Esse tema cnvolve o descnvolvimento de aplicações que levam em consideração uma colcção de informações de contcxto e permite um comportamento dinâmico de sistemas de acordo com o conhecimento do ambiente. Localização é um tipo de informação de contexto

\footnotetext{
${ }^{1}$ Nesta disscrtação, o termo "contexto", definido por Dey, scrá empregado para denotar "informaçóes de contexto".
} 
utilizada, por exemplo, no desenvolvimento de sistemas baseados na navegação por GPS (Global Positioning System). No entanto, devem ser utilizados outros tipos de informações para se representar um contexto, embora muitas aplicações utilizem apenas identificação de usuário e local. Conhecimentos sobre o tempo, o histórico (recente ou antigo) e outras pessoas presentes em $1 \mathrm{~m}$ ambiente representam algumas dessas informações.

Beigl et al. [Beigl et al., 2002] defendem a idéia de que a localização é um dos elementos de contexto mais importantes na computação ubíqua. Como resultado, esses pesquisadores desenvolveram um modelo de localização ciente do espaço. Trata-se de uma infra-cstrutura que pode ser adaptada tanto em dispositivos de alta capacidade quanto em pequenos sistemas computacionais embutidos em objetos do dia-a-dia. O protótipo MediaCup, por excmplo, pode ser embutido em xícaras de chá equipadas com ferramentas que realizam comunicação, sensoriamento e processamento (Figura 2.3 da esquerda). Dessa forma, uma xícara é capaz de prover informações sobre seu cstado - "algućm está bebendo" ou "estou quente" — para outro objeto que esteja por perto. O MemoClip [Beigl, 2000] é outra aplicação construída por Beigl e pode ser cmbutida em pequenos grampos presos à roupa (Figura 2.3 da direita). O objetivo é informar o usuário do objeto sobre as atividades que devem ser feitas dependendo do local onde se encontra.

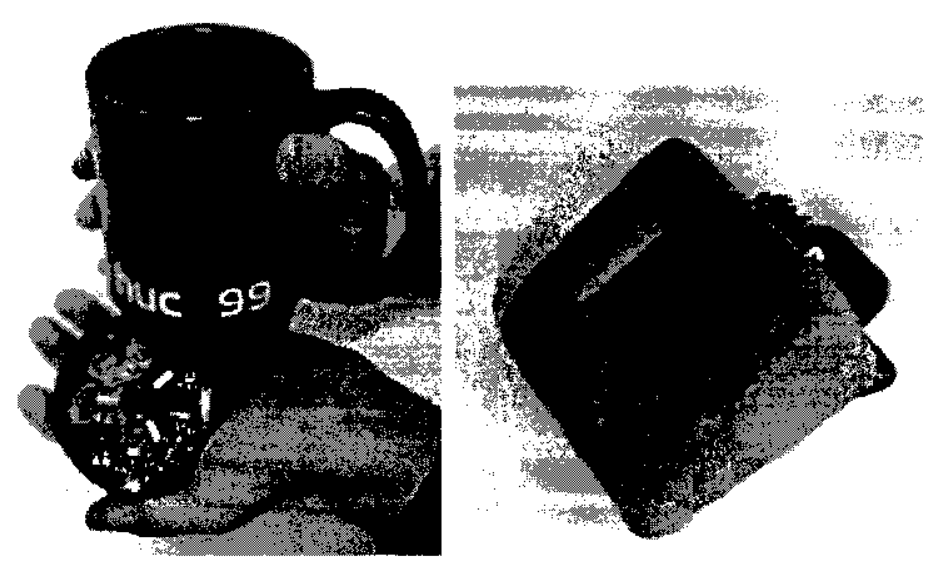

Figura 2.3: Esquerda: McdiaCup, ilustração de um artefato digital. Direita: MemoClip, um grampo preso à roupa que procura por informações de localização do usuário.

Em 1999, pesquisadores do GATECH deram início à construção da Aware Home (Figura 2.4), um ambiente dotado de dispositivos e serviços computacionais com capacidade para reconhecer informações sobre si mesma e sobre a localização e as atividades de seus habitantes 
[Kidd et al., 1999]. Por cxcmplo, existem sensores adaptados no solo que podem identificar e rastrear indivíduos em uma grande área. São várias as aplicações para a tccnologia de scnsores, incluindo suporte para idosos on para encontrar objetos perdidos.

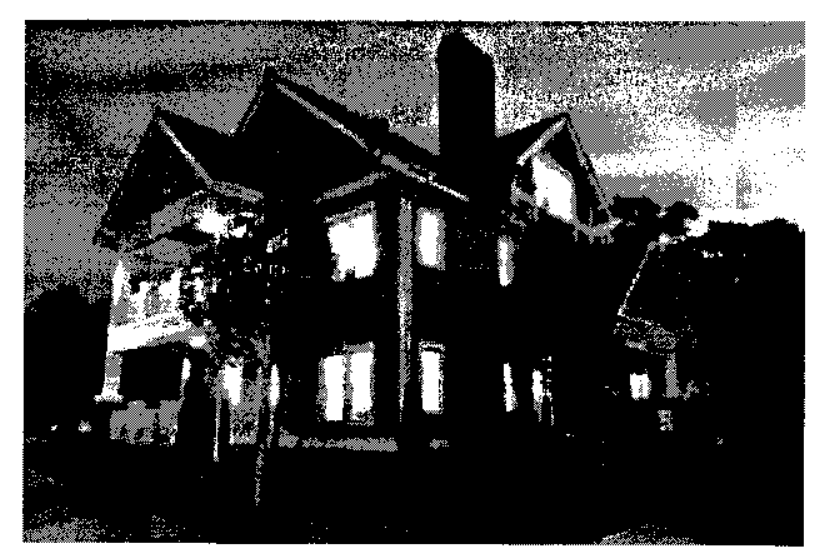

Figura 2.4: Aware Horne: residência utilizada como laboratório para pesquisas de computação ubíqua.

Entretanto, o progresso na árca de sensores precisa ser acompanhado pelo desenvolvimento rápido de aplicações que utilizam informações scnsoriais. Nesse sentido, Salber et al. [Salber et al., 1999 ] desenvolveram uma infra-cstrutura de software para auxiliar a construção de aplicações cientes de contexto. Trata-sc do Context Toolkit, um conjunto de ferramentas baseadio no conccito de widgets de contexto ${ }^{2}$. Tais como widgets de interface estão cntre a aplicação e o usuário, os widgets de contexto estão localizados entre a aplicação c seu ambiente de operação c, além disso, possuem características de ocultar a complexidade dos sensores utilizados pela aplicação, de abstrair informações de contexto c de prover reusabilidade.

O Context Toolkit foi utilizado nos trabalhos de Covington et al. [Covington et al., 2001] durante o desenvolvimento de um modelo de controle de accsso, visando a segurança de aplicações cientes de contcxto. No caso da Aware Home, políticas de segurança podem restringir o accsso a informações ou recursos de acordo com vários fatores, incluindo atributos sobre o indivíduo --.- adultos ou crianças, proprietários ou hóspedes - - ou sobrc o ambicnte temperatura ou horário. Existem vários cenários de uso de políticas de segurança, contanto que existam informações relevantes em um ambicnte que possam sor capturadas e usadas

\footnotetext{
${ }^{2}$ Componentes de software que provêem informações de contexto para aplicações em um determinado ambiente de operação.
} 
para restringir o acesso a recursos do sistema.

Uma outra aplicação que utiliza o Context Toolkit ć o Family Intercom [Nagel et al., 2001]. O protótipo inicial foi instalado na Aware Home com o objetivo de explorar informações de contexto para dar suporte à comunicação dentro da própria casa entre membros de uma família. O modo de interação com a aplicação ó por meio de voz e, portanto, existem equipamentos de áudio espalhados pela casa, incluindo alto-falantes, microfones sem fio c comutadores, além de sistemas de posicionamento. O segundo protótipo foi construído para explorar a comunicação entre famílias de casas distintas. Nesse cenário, existem monitores sonsíveis ao toque (com formato semelliante ao de um porta-retrato), equipamentos de áudio e um sistema para identificação de indivíduos. Através do porta-retrato digital, os membros de uma família se comunicam entre si e são capazes de perceber informações contextuais sobre a qualidade de vida de seu parente (Figura 2.5). Por exemplo, condições do ambiente, relacionamento com outras pessoas, atividades físicas e ocorrência de eventos especiais [Mynatt et al., 2001] são informações que podem indicar o bem-estar de uma pessoa idosa.

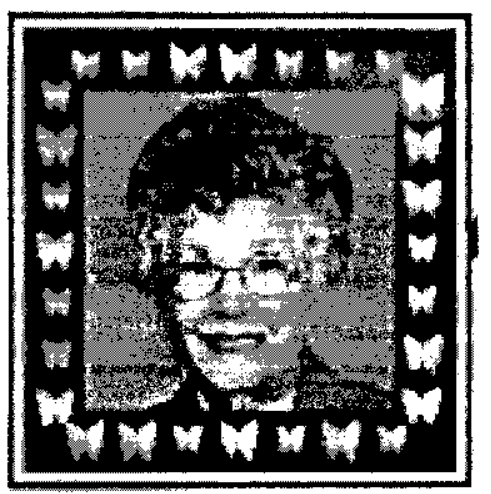

Figura 2.5: Family Intercom: porta-retrato utilizado para comunicação entre famílias em casas distintas.

\subsection{Captura e Acesso a Informações}

Uma das características de ambientes de computação ubíqua é sua utilização visando a captura de cxperiências do cotidiano e tornando os registros disponíveis para acesso pelos usuários-finais [Abowd, 1999]. De fato, na maior parte do tempo, as pessoas encontram-se registrando, com maior ou menor precisão, os eventos que estão a sua volta. Posteriormente, de acordo com a necessidade do usuário, deseja-se que parte das informaçōes possam ser 
recuperadas. Nesso sentido, a utilização de ferramentas especializadas na tarefa de registrar informação possibilita que as pessoas se concentrem na síntese e compreensão da experiência propriamente dita, com total confiança de que os detalhes estão sendo registrados e serão disponibilizados para futuras consultas.

As experiências do cotidiano podem ser vistas como geradoras de rico conteúdo multimídia. Prover mecanismos automatizados para a captura, integração e acesso a esses registros multimídia é um dos desafios da computação ubíqua.

O Projeto eClass, originariamente desenvolvido no GATECH, investiga a utilização de computação ubíqua para a captura de informações cm ambicntes de salas de aula convencionais, de modo a permitir a produção automática de documentos hipermídia que refletem o conteúdo capturado e a apresentação desse material através da Web [Abowd ct al., 1998a] [Abowd et al., 1998b] [Brotherton e Abowd, 1998] [Brotherton et al., 1998].

O cClass é constituído por duas infra-estruturas: uma de hardware e outra de software. A infra-estrutura de hardware, presente em uma sala de aula instrumentada, consiste tipicamente de uma lousa eletrônica (whiteboard), projetores, microfones e câmera de vídeo. Na Figura 2.6 apresentamos a sala protótipo inicial, em operação no GATECH desde Janciro de 1997. Nessa sala estão presentes uma lousa eletrônica (A), uma câmera do vídeo (B), vários microfones cmbutidos no forro (C) e dois projetores (D e E), tudo operando sincronizadamonte através de um conjunto de módulos de software cliente-servidor.

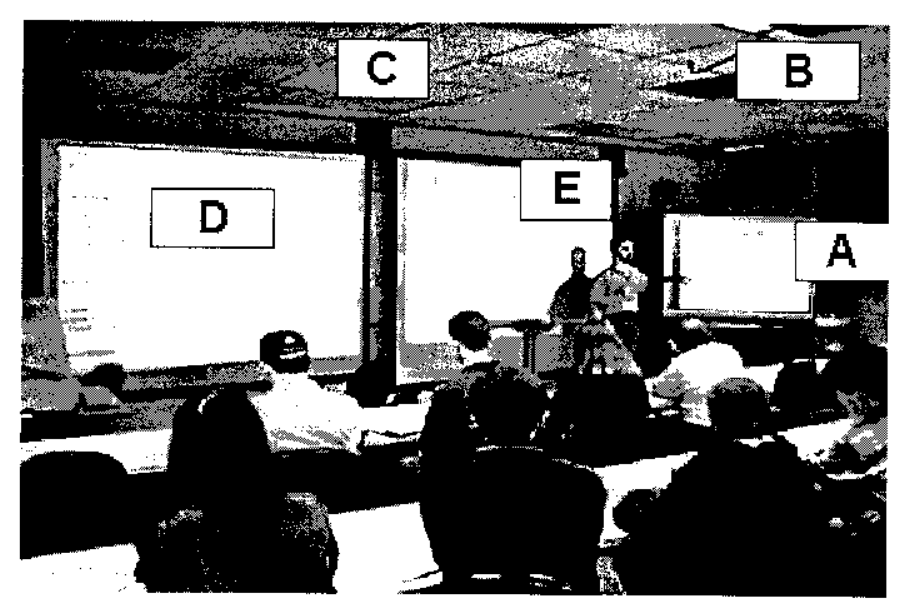

Figura 2.6: Sala de aula instrumentada. 
A infra-estrutura de software, refcrenciada como Zen* system, é responsável pela captura e sincronização dos fluxos de informação durante cada scssão ao vivo. Suas tarefas incluem ainda a geração dos documentos associados quando a sessão é encerrada. Como resultado desse processo, poucos minutos após a conclusão da sessão, um hiperdocumento Web é automaticamente gerado e disponibilizado para acesso [Pimentel et al., 2000].

As experiĉncias adquiridas através da criação da infra-estrutura do Projeto eClass permitiram aos pesquisadores do GATECH a elaboração de um sistema cliente-servidor, chamado StuPad [Truong c Abowd, 2004]. Neste sistema, é utilizada uma abordagem para a personalização de captura de experiências públicas. Para tanto, são fornecidos aos alumos computadores sensíveis ao toque de caneta (tablets) para anotações pessoais. Depois de cada aula, as anotaçõcs pessoais são automaticamente ligadas ${ }^{3}$ ao áudio gravado previamente durante a aula. Esse sistema está representado na Figura 2.7. Na imagem (A), a lousa clctrônica captura os slides e as anotações do professor e o tablet captura as anotações do aluno. Na imagem (B), ć apresentada uma ampliação do slide da lousa eletrônica. A imagem (C) contém uma cópia dos slides da lousa que foram automaticamente integrados com as anotações pessoais do estudante.

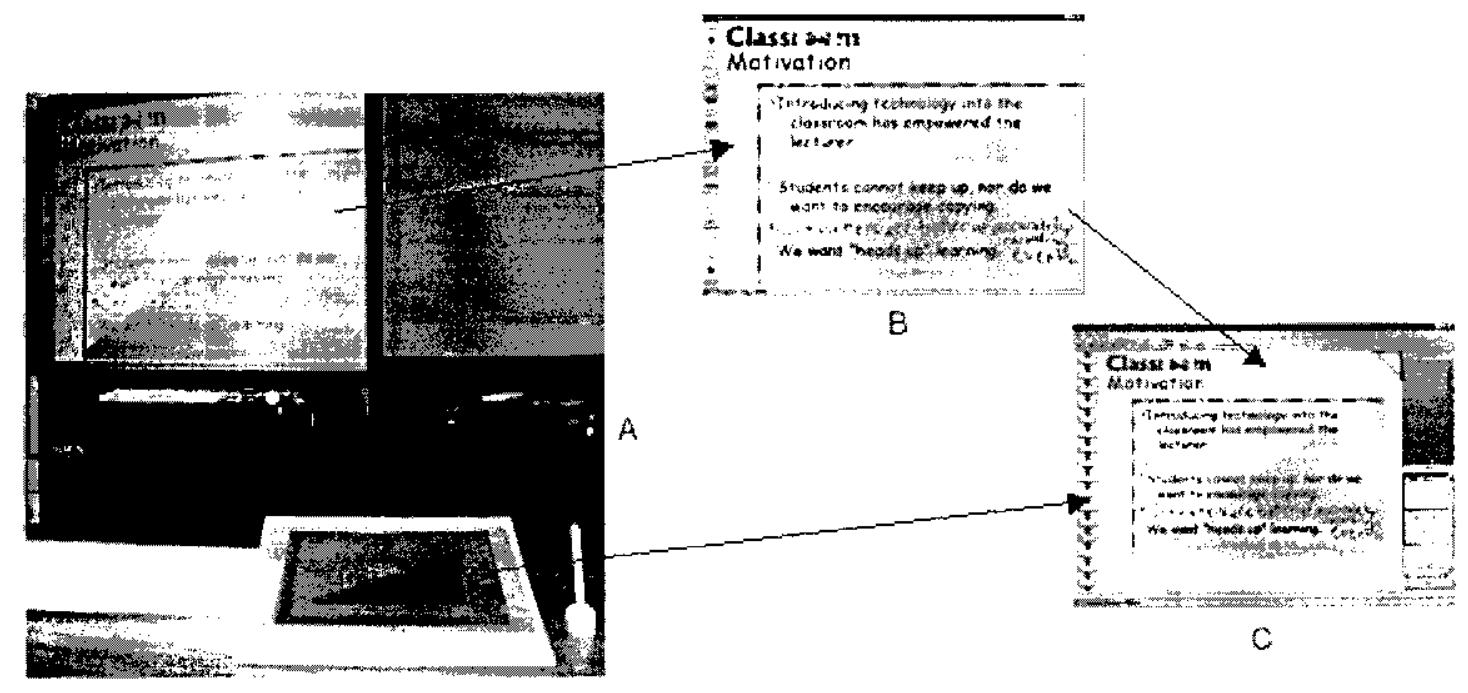

Figura 2.7: O sistema StuPad usado em sala de aula.

O NotcPals [Davis et al., 1999] é outro sistema responsável por capturar anotações de membros de um grupo, bem cono algumas informações sobre o contexto no qual essas

\footnotetext{
${ }^{3}$ As anotaçõcs são índices para o fluxo de áudio.
} 
anotações foram escritas, tais como o autor, o tópico c a hora em que elas foram criadas. Após a captura, as anotações são armazenadas em um repositório compartilhado que pode ser acessado através de um navegador convencional pelos membros do grupo. Tais navegadores pcrmitcm aos membros reaverem todas as anotações tomadas em um dado contexto, ou acessá-las através de outros documentos ou anotações relacionados.

Como temos observado, os sistemas citados anteriormente podem ser aplicados a ambientes educacionais e de rcunião, mas também existcm aqucles que são voltados para ambientes de conferência. Um cxcmplo é o Conference Assistant [Dey et al., 1999], uma aplicação de captura e acesso que permite aos usuários a realização de anotações nos locais de aprcsentações, demonstraçõcs ou reuniões de grupos de interesse. Para tanto, são fornecidos PDAs aos participantes para uso durante a conferência. Ao término desta, as anotações de cada participante podem ser integradas com as apresentações previamente capturadas. Além de se comportar como uma aplicação de captura c acesso, o Conference Assistant também agrega informações de contexto, isto é, apresentações são capturadas e rotuladas de acordo com o local em que foram realizadas.

Embora haja muitas demonstrações de aplicações de captura e acesso, construí-las e mantĉ-las não é uma tarefa trivial. Constituídas de uma confederação de componentes que precisam trabalhar juntos de maneira harmoniosa, essas aplicações geralmente consomem muito tempo de implementação e requcrem familiaridade, senão mesmo expertise, em uma grande variedade de domínios de problema, por cxemplo, sistemas distribuídos, sistcmas hipermídia, programação concorrente e computação móvel.

Devido a sua natureza distribuída c ao grande número de dispositivos envolvidos, a construção de aplicaçóes de captura e accsso constitui-se em um desafio à partc e é, geralmento, fcita de maneira ad hoc, objotivando um uso específico e desconsiderando propostas de cxtensão e rcuso. O eClass é um exemplo de aplicação de captura e accsso construído segundo essa abordagem. De acordo com Truong [Truong c Abowd, 2004], é neccssário um modelo de desenvolvimento que permita a prototipação rápida de uma aplicação de captura c acesso, sua implantação e sua modificação de acordo com uma rcalimentação contínua por parte da comunidade de usuários. As ferramentas dessc modelo devem suportar aspectos de estruturação de software, correta separação de interesses (separation of concerns) c técnicas 
de integração de componentes de software para uma grande variedade de dispositivos e sistemas operacionais. Outro aspecto importante na construção de aplicações de captura e accsso refere-sc ao espaço de projeto. Truong et al. [Truong et al., 2001] definem cinco dimensôes para o projeto de aplicações de captura e acesso:

- (Who) Quem são os usuários durante as fases de captura e acesso? É importante identificar quantos usuários estão envolvidos, quais os seus papéis no domínio da aplicação e se os registros capturados são públicos, privados ou uma combinação de ambos;

- (What) O que é capturado e acessado? Define-se a experiência em termos dos artefatos manipulados c dos fluxos de informação gerados, quais são importantes para consulta futura e em que nível de granulosidade;

- (When) Quando a captura e o acesso ocorrem? Deve-se identificar com que freqüência a captura e o acesso ocorrem, se há algum padrão passível de previsão c o tempo que se passará entre a cxpcriência capturada e o acesso;

- (Where) Onde a captura e o acesso ocorrem? São considerados aspectos de localização física e de mobilidade durante a captura e o acesso;

- (How) Como são feitos a captura e o acesso? Identificam-se quais ferramentas c dispositivos são necessários para a fase de captura e para a fase de acesso.

A INCA (Infrastructure for Capture \& Access Applications) ć uma infra-estrutura de software, escrita cm linguagem Java, projetada para simplificar a implementação de aplicações de captura e acesso [Truong e Abowd, 2004]. Sua arquitetura busca abstrair a natureza distribuída de sistemas de computação ubíqua separando aspectos pertinentes à captura, armazenamento, conversão, integração c accsso à informação.

O Projeto InCA baseia-se no fato de que aplicações de captura e acesso apresentam muitas similaridades arquiteturais: parte do sistema é responsável pela captura da informação; parte do sistcrna é responsável pelo armazenamento da informação capturada; quando múltiplos fluxos de informação são capturados ao mesmo tempo, parte do sistema é responsável pela integração dos pedaços de informação correlatos; quando parte da informação precisa ser 
convertida para diferentes formatos ou tipos de dados, alguma parte do sistema precisa prover um mecanismo de conversão; e parte do sistema é responsável pelo acesso à informação capturada. A existência dessas similaridades sugere que parte do projeto de aplicações do captura e acesso possa ser modularizado. A INCA provê suporte para cada uma das fases envolvidas (captura, armazenamento, integração, conversão e acesso) através de módulos. Cada um dos módulos consiste de uma classe para dispositivos c aplicações que implementam uma respectiva interfacc. Assim, para implementar a parte do sistema responsável pcla captura, é neccssário também implementar a interface de captura (Capturer) e possuir uma instância do módulo de captura (CaptureModule).

A xINCA (Extended Infrastructure for Capture \& Access Applications) ć uma extensão da infra-cstrutura INCA e oferece um conjunto de componentes, cada um responsável por uma funcionalidade específica, dentre as citadas acima, no contexto de aplicações de captura e acesso [Cattelan et al., 2003]. A infra-estrutura xINCA foi projetada como uma camada acima da infra-estrutura INCA, utilizando-se dos módulos e paradigmas de abstração da mesma

Usando a infra-estrutura xINCA, uma nova aplicação de captura e acesso é construída através da instanciação c do agrupamento dos componentes desejados. Componentes de uma mesma classe comunicam-se através de um número de identificação de sessão. Uma sessão caracteriza um período de interação entre componentes xINCA e deve possuir um identificador único durante scu tempo de duração. Novas instâncias dos componentes xINCA, constituintes das aplicaçõcs, podem ser adicionadas e removidas a qualquer instante durante a vida útil de uma sessão.

Os componentes xINCA possuem instâncias dos módulos INCA de captura, de acesso, ou de ambos. Esses módulos são registrados, scgundo seu identificador de sessão e em tempo de cxecução, em um componente de registro (Registry) da infra-estrutura INCA, o qual pode ou não ser remoto. Componentes XINCA, dotados de módulos INCA, estão habilitados a trocar informação cntre si desde que estejam registrados cm um mesmo Registry sob um mesmo identificador de sessão.

Na Figura 2.8 é ilustrado, em linhas gerais, o fluxo de comunicação entre componentes 
xINCA para duas sessões simultâneas. No lado esquerdo, encontra-se uma aplicação (App) \#1) de captura e acesso com dois componentes xINCA, um para chat e outro para whitcboard. No lado direito superior, encontra-se uma aplicação (App \#2) de captura e acesso com um componente xINCA para chat. Por fim, no lado inferior direito, há uma aplicação de acesso com um componente xINCA para whiteboard (App \#3). Os componentes chat da App \#1 e da App \#2 estão registrados sob o mesmo identificador de sessão (Sessão \#1), ou seja, possuem um canal de comunicação ativo e são capazes de trocar informação. Da mesma forma, os componentes xINCA para whiteboard da App \#1 e da App \#3 também cstão registrados sob um mesmo identificador de sessão (Sessão \#2) e trocam informação. Especificamente para esse caso, a comunicação é unidirecional, pois a App \#1 apenas captura informação c a App \#3 apenas acessa a informação capturada. Atualmente, os componentes xINCA existentes são os de whiteboard, chat, áudio, vídeo e web logging ${ }^{4}$.

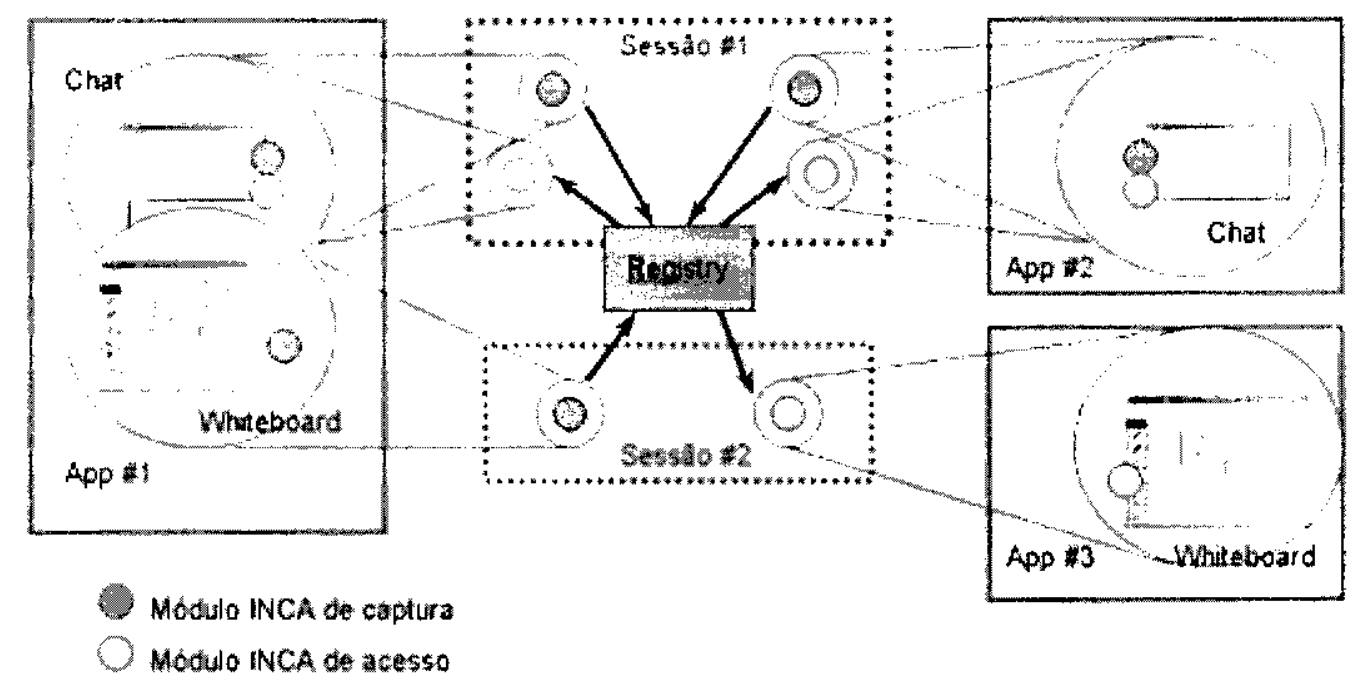

Figura 2.8: Comunicação entre os componentes XINCA de whiteboard e chat.

Vale ressaltar que o accsso às informações capturadas fornecido pela infra-estrutura XINCA é do tipo síncrono apenas. Cabc à aplicação armazenar informações capturadas para accsso

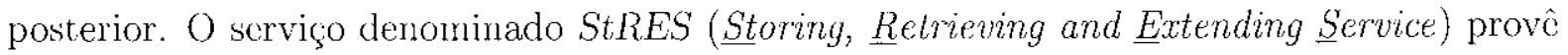
tal suporte [Baldochi et al., 2003]. Esse serviço tem como objetivo propor um modelo de armazenamento quo contemple a característica evolucionária das informações manipuladas por aplicações de captura e acesso. Trata-se de um scrviço ubíquo que visa favorecer o de-

\footnotetext{
${ }^{4}$ Consiste no armazenamento dos endereços das páginas visitadas durante uma sessão de captura.
} 
senvolvimento de aplicações desse tipo. O StRES é resultado da implementação de diversos módulos (sub-serviços) integrados cm uma arquitetura capaz de oferccer às aplicações acesso transparente a um repositório de informações evolucionárias, estendendo, dessa forma, a arquitetura básica da INCA, segundo a qual cabc às aplicaçōes gerenciar o armazenamento, recuperação e extensão do material capturado.

A xINCA serviu de base para a construção do Sistema iClass ${ }^{5}$, visando a captura de aulas em ambiente instrumentado [Cattelan et al., 2003]. O iClass é uma cxtensão do eClass c consiste basicamente de uma applet Java incluindo componentes xINCA de captura, de acordo com a funcionalidade desejada (whiteboard, áudio e vídeo). As informações produzidas durante uma aula, como slides, anotações ou áudio são armazenadas pelo StRES em um repositório comum, de forma que o material possa scr revisitado posteriormente a partir da Web. Na Figura 2.9 ilustramos uma aula sendo gravada no ICMC-USP através de uma lousa elctrônica. Podemos obscrvar um slide projetado na lousa e as anotações (traços) feitas sobre cle. Tanto os slides quanto as anotações fazem parte e são controlados pelo componente xINCA de whiteboard.

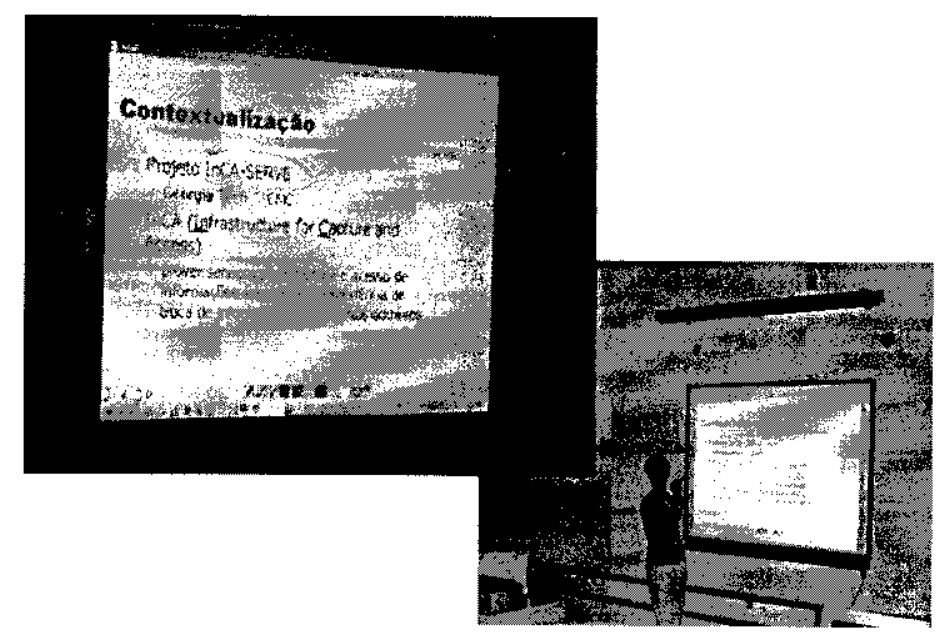

Figura 2.9: Captura de uma aula pelo Sistema iClass.

No Capítulo 4 apresentamos mais detalhes sobre as fases que compõem o Sistema iClass e sobre o esquema de armazenamento utilizado pelo StRES, uma vez que cste trabalho está integrado com os módulos desse serviço. Na próxima seção abordamos as considerações finais deste capítulo.

\footnotetext{
${ }^{5}$ ht tp: $/ /$ iclass.icme.usp.br
} 


\subsection{Considerações Finais}

Aplicações de computação ubíqua compartilham várias características funcionais. Há um grande esforço para que essas aplicaçooss suportem mecanismos de transparência de interação, adaptem seu comportamento de acordo con as mudanças de contexto e forneçam serviços automatizados para captura de experiências ao vivo c acesso às informações capturadas.

Em paralelo, temos observado um grande avanço no númcro de componentes de hardware de custo e tamanho reduzidos, favorecendo a criação de novos produtos embutidos em objetos convencionais do dia-a-dia. Enquanto o uso ubíquo da computação pode trazer bencfícios, ao mesmo tempo ele impõe novos desafios no projeto de interfaces e de aplicações responsáveis por capturar informações contextuais. Isso leva a uma mudança na relação existente entre humanos e computadores. Ao fornecer modelos de interação contínua com o computador, a computação ubíqua transforma os dispositivos em uma ferramenta de presença constante no ambiente.

Este trabalho está apoiado nos conceitos da computação ubíqua, mais precisamente sobre os temas de interfaces naturais e captura e acesso a informações. Em relação a intcrfaces naturais, desenvolvemos um mecanismo de rolagem de toxto para auxiliar a tomada de anotações, realizamos um experimento controlado com usuários e avaliamos esse mecanismo segundo técnicas de avaliação padrão de HCl. Além disso, também avaliamos o impacto causado pela utilização de uma árca de anotações maior que a tela de PDAs através de um segundo experimento. Os detalhes do planejamento desses experimentos, os resultados e as conclusões são discutidos no próximo capítulo. 


\section{Capítulo 3}

\section{Anotações com Área de Escrita}

\section{Ampliada}

\subsection{Considerações Iniciais}

$O$ uso de dispositivos portáteis, como os PDAs, traz muitas vantagens que auxiliam os usuários na realização de tarefas do dia-a-dia. Para citar alguns exemplos, o uso de PDAs foi rclatado em hospitais [Muñoz et al., 2003], permitindo que os usuários enviem mensagens e acessem scrviços quando e onde for necessário; cm salas de aula [Tatar et al., 2003], aumentando a interação dos alunos com dados e idćias; o cm jogos educacionais para o aprendizado de artes e história [Bellotti et al., 2003].

Recentemente, investigaçoes têm sido feitas para avaliar usuários quanto ao acesso a informações em dispositivos com tela pequena. Jones et al. [Jones ct al., 2003] conduziram um experimento para avaliar a interação de usuários com uma interface de busca ná Web e chegaram à conclusão de que o tempo para se completar uma tarefa de busca cm uma interface para celular foi maior que o tempo em PDAs, que, por sua vez, foi maior que o tempo en urn computador pessoal (PC) convencional. Com esse resultado, os autores propuscram algumas guidelines para melhorar interfaces de busca e algumas idćias para representação mais adequada de resultados de busca em PDAs. Um trabalho semelhante 
foi conduzido por Watters et al. [Watters et al., 2003] na tentativa de avaliar o esforço e o desempenho de buscas por dados em tabelas que sâo consideravelmente maiores que a tela do dispositivo.

Outros trabalhos investigam o processo do leitura em telas pequenas, utilizando técnicas como o RSVP (Rapid Serial Visual Presentation), que permitem apresentações dinâmicas de textos como blocos de palavras. Öquist c Goldstein [Öquist o Goldstein, 2003] relatam um estudo de usabilidade com 16 usuários c discutem algumas abordagens para um RSVP que se adapta ao conteúdo dos blocos de texto. Entre outros resultados, essa abordagem aumentou a velocidade de leitura c a compreensão do texto. Em rclação aos trabalhos de interfaces para celular, Buchanan et al. [Buchanan et al., 2001] realizaram um estudo de caso sobre diferentes formas de rolagem de texto para leitura de manchetes na tela de celulares e propuseram algumas guidelines para o desenvolvimento de serviços para esses dispositivos.

A crescente utilização de PDAs induz o aparecimento de novos desafios de usabilidade a fim de torná-los mais atracntes para usuários em geral. Entretanto, o tamanho da tcla é uma das limitações mais críticas desses dispositivos . em particular quando usuários têm que accssar e interagir com grande volume de informação. Conseqüentemente, a rolagem do contcúdo informativo torna-se necessária para possibilitar a visualização de toda a área de interesse, embora possa interromper a tarefa e não seja recomendada para aplicações de PCs convencionais (particularmente na Web [Nielsen, 1996]).

Yec [Yee, 2003] propôs o Pcephole como uma alternativa para os métodos de rolagem tradicionais. Nesse sistema, a rolagem ocorre de acordo com o movimento do próprio dispositivo, sendo que o rastreamento é realizado por equipamentos especializados. A idéia é que a mão não-dominante controle a navegação de modo que a mão dominante esteja livre para especificar as operações durante a interação. Yce realizou uma avaliação de usabilidade com 24 usuários, obtendo resultados bem sucedidos cm termos da intcração utilizada nas tarefas, embora tonha destacado as limitaçǒcs referentos ao rastreamento dos movimontos do PDA.

Nestc trabalho, claboramos um mecanismo de rolagem automática de textos durantc a realização de anotações em uma região virtual que cxtrapola os linnites da tela dos PDAs. Como consideramos que a velocidade de anotação é um fator importante durante atividades 
ao vivo, nosso objetivo neste capítulo é apresentar os resultados da aplicação de dois experimentos ${ }^{1}$ para avaliar a aplicabilidade do mecanismo empregado. Para isso, na Seção 3.2 apresentamos as atividades envolvidas com o expcrimento da rolagem de textos e, na Seção 3.3. avaliamos a questão da orientação espacial do usuário na região virtual. Por fim, na Seção 3.4 apresentamos as considerações finais deste capítulo.

\subsection{Mecanismo de Rolagem de Textos em PDAs}

Primeiramente, vamos apresentar os aspectos da interface do sistema que desenvolvemos para a execução desse experimento. Na imagem esquerda da Figura 3.1 podemos observar os seguintes componentes da interface: (A) janela na qual anotações podem ser feitas, ou simplesmente janela de anotação; (B) título da anotação atual (slide); (C) miniatura da janela de anotação; (D) botão que permite alternar entre os modos de deslocamento manual ${ }^{2}$ e escrita; (E) botões de navegação entre slides; e (F) contador de slides. A janela de anotação é a parte visível de unra área maior, que chamaremos de área virtual (Figura 3.1 à direita).

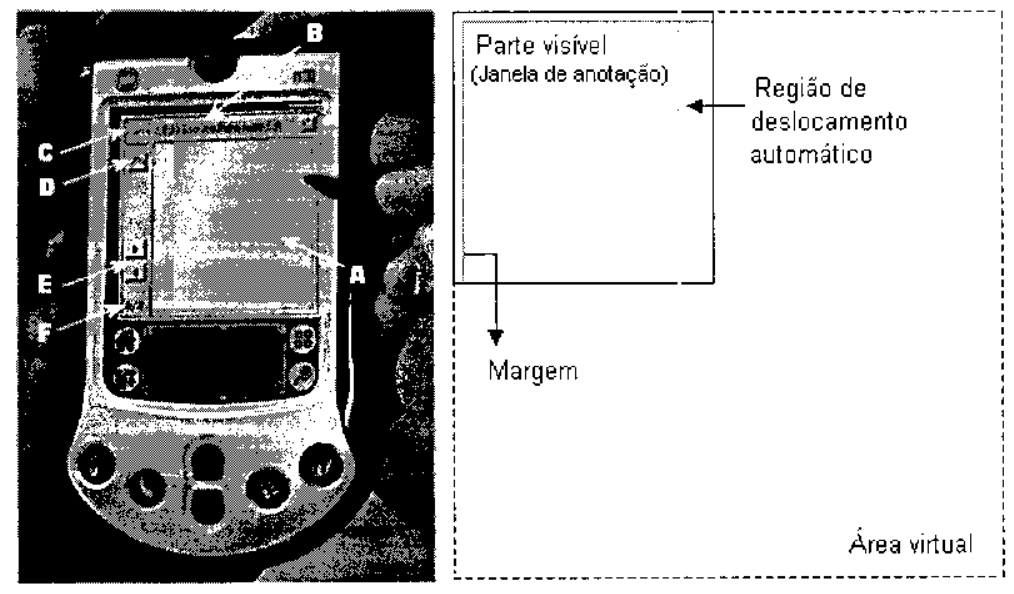

Figura 3.1: Esquerda: interface utilizada no experimento. Direita: ilustração da jancla de anotação e da área virtual.

No modo de deslocamento manual, o usuário é capaz de navegar por toda a área virtual através de interaçōes do tipo "arrastar o soltar", visualizando, inclusive, as margens que delimitam o espaço de anotação. Para tentar evitar que o usuário desvic sua atcnção da

\footnotetext{
'Para a realização desse experimento contamos com a colaboração do Professor Dorival Leão Pinto Júnior.

${ }^{2}$ No decorrer deste texto, utilizaremos o termo "deslocamento" para designar a rolagem (scrolling) de texto.
} 
tarefa de escrita, interrompendo-a com sucessivos deslocamentos manuais, elaboramos o mccanismo de deslocamento automático da área virtual. Assim, quando os traços da cscrita sc aproximam da região direita da janela de anotação, a área virtual é instantaneamentc transladada para a esquerda, permitindo que a escrita se estenda por toda a linha. De acordo com a metáfora convencional dos editores de texto, quando o final da linha é alcançado, a área virtual é inteiramente deslocada para a direita, posicionando-se no início da próxima linha.

No sistema em questão, a escrita pode ser fcita com a própria caneta que acompanha o dispositivo. Vale ressaltar que o deslocamento automático só acontece quando o usuário cstá no modo de cscrita c quando a caneta está posicionada na região direita da jancla de anotação. Nada acontece, portanto, se a caneta for posicionada nas regiões supcrior, inferior ou esquerda da tela.

\subsubsection{Planejamento}

Esse experimento tem como objetivo avaliar o impacto do mecanismo de deslocamento automático sobre os usuários de dispositivos portáteis, tendo em mente as seguintes questões:

- O usuário é capaz de sc adaptar facilmente ao deslocamento automático?

- Qual é o tempo gasto por cle para escrever uma frase com e sem deslocamento automático?

- Existem difcrenças entre usuários leigos (pouca ou nenhuma familiaridade com dispositivos portátcis) c usuários cxperientes?

Para responder a cssas questõcs, definimos um conjunto de fatores de influência, ou variáveis de controle, em que a alteração dos valores produz uma saída com uma ou mais respostas obscrvadas. São eles:

1. Tipo do deslocamento - refere-se à classificação do deslocamento (automático ou manual) utilizado pelo usuário durante a execução da tarefa; 
2. Tipo de usuário - refere-se ao tipo de usuário (leigo ou experiente) que está utilizando o sistcma. O usuário é classificado de acordo com sua habilidade de interação com PDAs;

3. Atividade - é o tipo de tarefa que o usuário realiza no PDA, compreendendo treinamento, preenchimento de uma curva c de três curvas e escrita livre ;

4. Ordem - diz respeito à forma em que uma atividade é iniciada, com ou sem deslocamento automático.

Existem também os fatores que vamos manter constantes. Eles até podem exercer algum efeito sobre a resposta, mas para o propósito desse experimento, não represcntam interesse. Portanto, cles foram mantidos em um nível específico:

1. Cor do traço - o usuário utiliza a cor vermelha para fazer os traços:

2. Espessura do traço "é a mais fina possível.

Depois que os fatores foram determinados, temos que sclecionar as variáveis de resposta. Tendo cm mente o objetivo desse experimento, elegemos duas variáveis de resposta:

1. Tempo - é a duração (cm segundos) da tarefa. O usuário dá início a uma determinada tarefa quando encosta a cancta na tela pela primeira vez. Essa tarefa é finalizada quando o último traço é fcito. O tempo decorrido entre esses dois eventos é a duração da tarefa;

2. Distância - ć um indicador da precisão de escrita ou desenho do usuário. A distância é medida em pixels c representa o espaço existente entre traços feitos pelo usuário e traços já existentes, os quais o usuário deveria sobrepor.

Em princípio, poderíamos utilizar apenas o tempo como variável de resposta. No entanto, resolvemos considerar a variável distância para obtermos resultados mais detalhados. Utilizando apenas o tempo, cstaríamos desconsiderando que a duração de uma tarefa pode ser reduzida caso os traços do usuário estejam suficientemente distintos daqueles que cle deveria sobrepor. 


\subsubsection{Exccução do Experimento}

O experimento foi conduzido de forma que cada usuário executasse oito tarefas distintas (tarcfas de A a H). Em cada uma delas, o usuário deveria sobrepor os traços preexistentes, feitos em cor preta, a menos na tarefa de escrita livre, na qual ó apresentada uma janela cm branco para o usuário. Metade das tarefas (A, B, C e D) exploram o deslocamento automático sobre os mesmos traços que são utilizados pela outra metade (E, F, G c H), utilizando deslocamento manual. Por outro lado, os usuários foram submetidos em diferentes ordens aos dois tipos de deslocamento, isto é, um grupo de usuários iniciou o experimento pelas tarefas de deslocamento automático, cnquanto outro grupo pelas tarefas de deslocamento manual, como detalhado adiante.

Antes de iniciarmos a primeira tarefa, apresentamos os detalhes da interface para o usuário tal como ilustrado previamente na Figura 3.1. Mais detalhes a respeito dessas tarefas são apresentados nas próximas seçõcs.

Tarefa A

A Tarefa A consiste no trcinamento do usuário com o deslocamento automático. Como podemos observar na Figura 3.2, existem très linhas horizontais estendendo-se por toda área virtual. Na imagem da direita, podemos observar um usuário percorrendo a linha mestra.

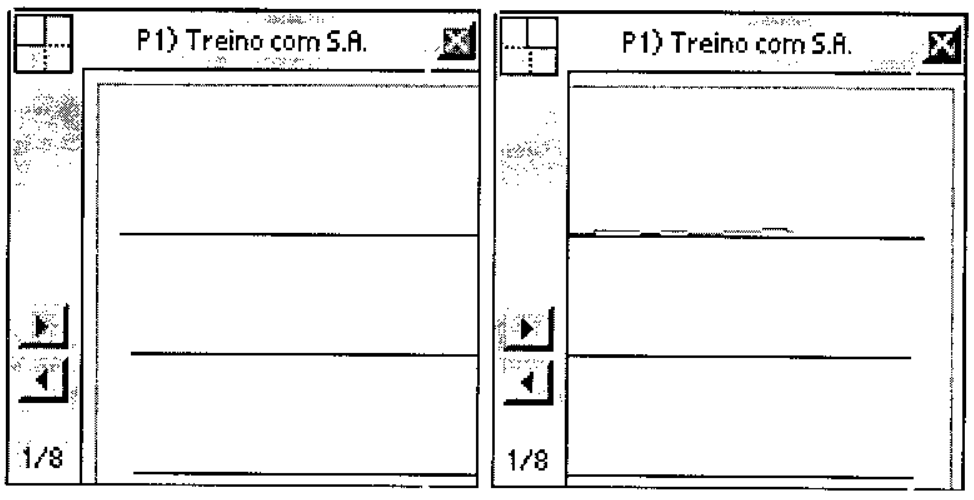

Figura 3.2: Tarefa A: treinamento do usuário. Escucurda: configuração inicial da tarefa. Direita: um usuário percorrendo as linhas mestras. 
Tarefa B

Na Tarefa B, o usuário deve cobrir uma curva simples, também com deslocamento automático. Nesta tarefa, existe apenas uma curva que se estende por toda área virtual (Figura $3.3)$.

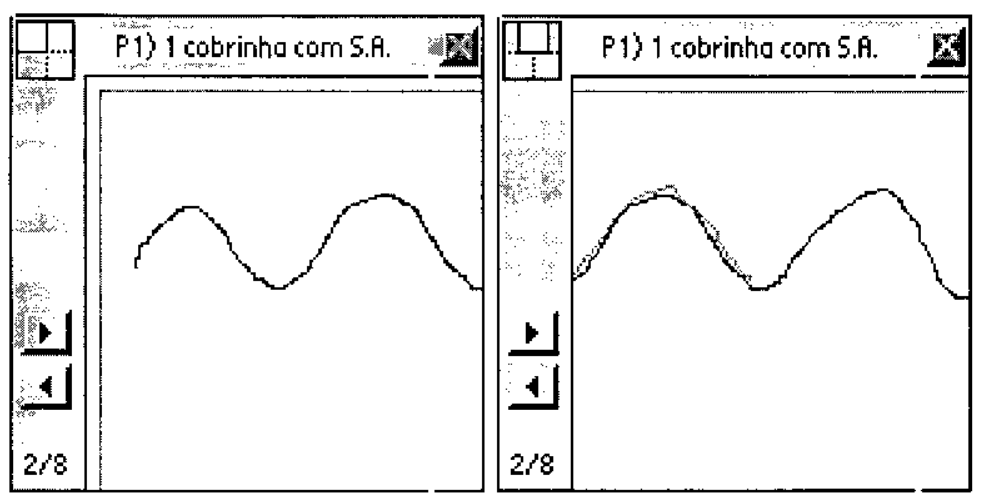

Figura 3.3: Tarefa 13: sobrepor uma curva simples. Esquerda: configuração injcial da tarela. Direita: um usuário percorrendo a curva.

Tarefa C

Para realizar a Tarefa C, o usuário deve sobrepor três curvas, utilizando deslocamento antomático. As curvas têm comprimentos diferentes e se estendem por toda área virtual (Figura 3.4).
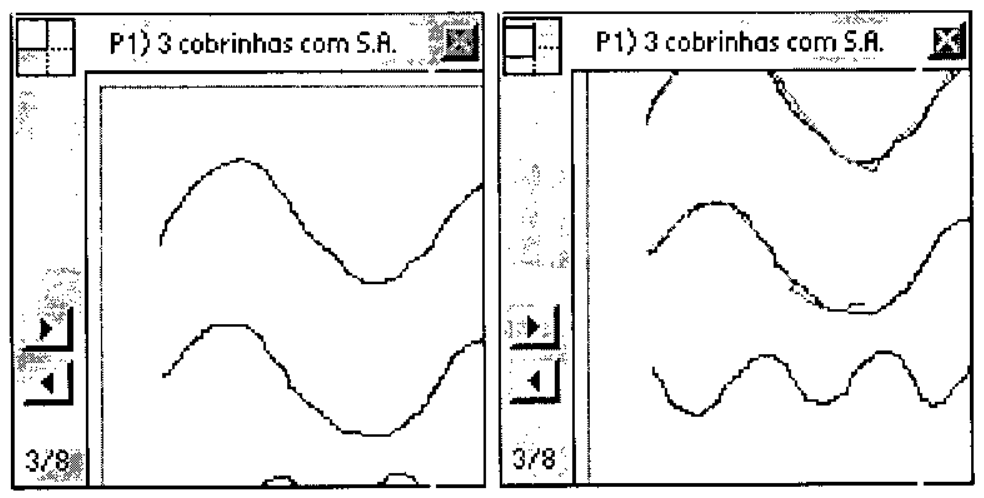

Figura 3.4: Tarefa C: sobrepor três curvas existentes. Esquerda: configuração inicial da tarefa. Direita: um usuário percorrendo o início da scgunda curva. 


\section{Tarefa D}

Na Tarefa $\mathrm{D}$, apresentamos uma janela em branco e pedimos que o usuário escrevesse a frasc "Feliz Natal e Próspero Ano Novo", também com deslocamento automático. Informamos ao usuário que o deslocamento automático não necessariamente deve ser utilizado (Figura 3.5).
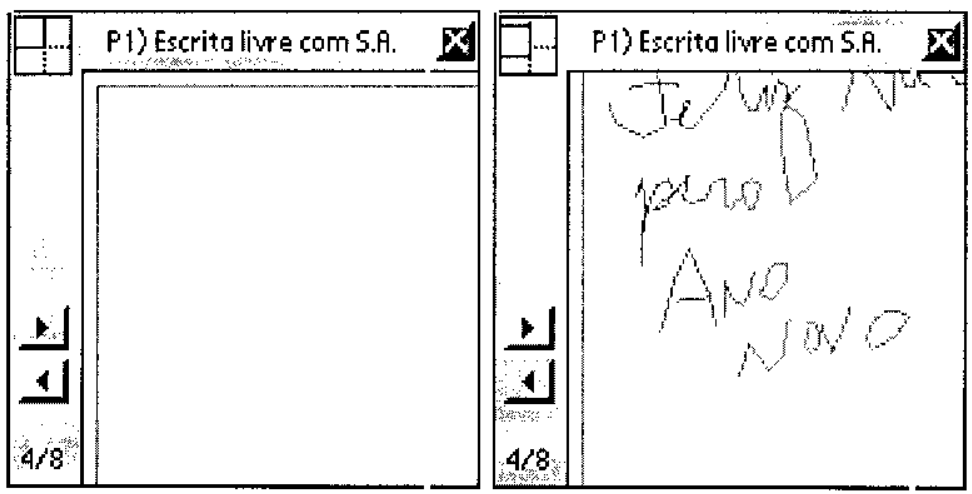

Figura 3.5: Tarcfa D: cscrita livre. Essquerda: configuração inicial da tarefa. Dircita: frase escrita por um usuário.

Tarefas E, F, G e H

Essas tarefas são análogas às antcriores. A Tarefa E corresponde à Tarefa A, a Tarefa F à Tarcfa B. e assim sucessivamente. Porém deve ser utilizado o deslocamento manual, simbolizado pelo botão na rcgião superior esquerda da tela. Na Figura 3.6, estão ilustradas as tarefas de treinamento c de acompanharnento das três curvas.
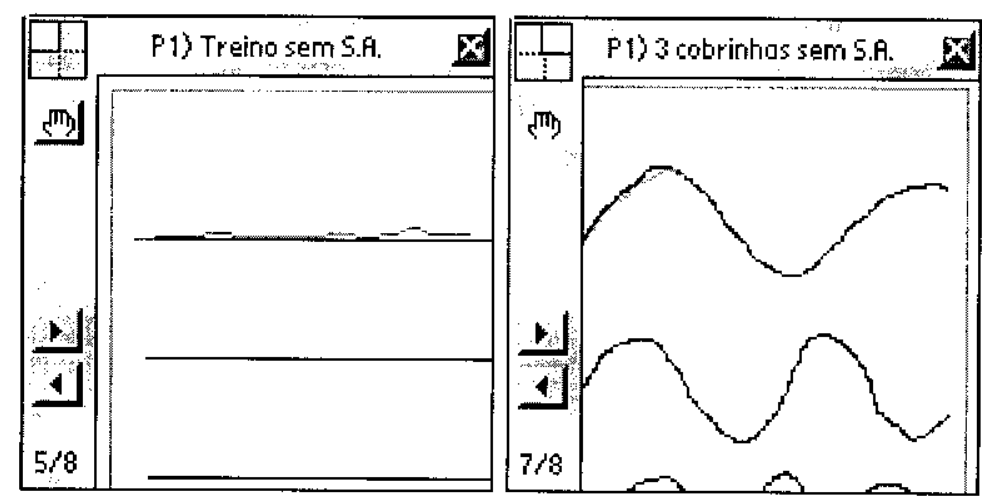

Figura 3.6: Esquerda: Tarefa E, de treinamento. Dircita: Tarefa G, das três curvas. 


\subsubsection{Análise dos Resultados}

O experimento foi realizado com 14 usuários, sendo 7 leigos e 7 cxperientes. Em relação ao fator ordem, 7 usuários iniciaram o experimento realizando as tarefas A, B, C e D. Os outros 7, realizaram inicialmonte as tarefas E, F, G c H. Daqucles que iniciaram com deslocamento automático, 4 eram loigos e 3 eram cxpericntes. Conseqüentemente, 3 leigos o 4 cxperientes iniciaram com deslocamento manual.

Primeiramente, verificamos sc existe correlação entre as variáveis respostas e obtivemos um P-valor igual a 0.274. Como o P-valor é maior do que 0.05, então rejeitamos a hipótese de que existe correlação entre as variáveis respostas, o que nos permite fazer uma análise individual de cada variável.

Em seguida, utilizamos um modelo de análise estatística - ANOVA - para analisar a influchcia dos fatores na variável resposta tempo. Os resultados indicaram que três fatores têm influchncia sobre o tempo: ordem $(\mathrm{F}=8.19$ c $\mathrm{P}<=0.005)$, tipo de deslocamento $(\mathrm{F}=20.11$ e $\mathrm{P}<0.001)$ e atividade $(\mathrm{F}=38.32 \mathrm{e} \mathrm{P}<0.001)$.

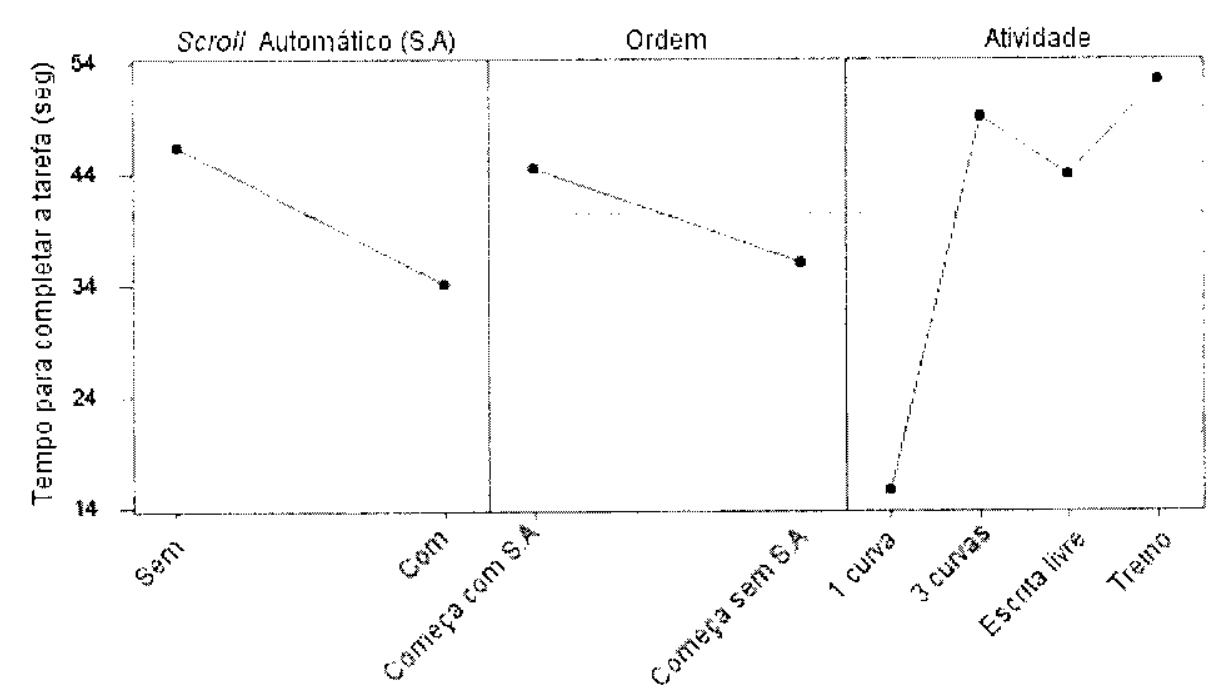

Figura 3.7: Fatores que influenciam o tempo para sc completar a tarefa: tipo de deslocamento, ordem e atividade.

O fator atividade era esperado ser significativo, pois representa diferentes tipos de traços com dificuldades variadas. A influência da ordem sugcre que usuários têm mais dificuldade para usar o deslocamento manual depois de usar o automático do que vice-versa. Com isso, 
podemos dizer que, depois de usar o deslocamento automático, o uso da técnica manual foi mais difícil, não importando a expcriĉncia do usuário. Finalmente, o uso do deslocamento automático reduz significativamente o tempo de execução das atividades ..... como está indicado pelo gráfico na Figura 3.7. Essc é um resultado importante com respeito a oferecer ou não esse tipo de opcração nos PDAs.

Novamente, nós usamos um modelo de ANOVA para analisar a influência dos fatores sobre a variável resposta distância. Os resultados indicaram que duas variáveis têm influchncia. sobrc a distância: tipo de deslocamento $(\mathrm{F}=3.88$ e $\mathrm{P}<=0.050)$ e atividade $(\mathrm{F}=3.61 \mathrm{e}$ $\mathrm{P}=0.032)$.

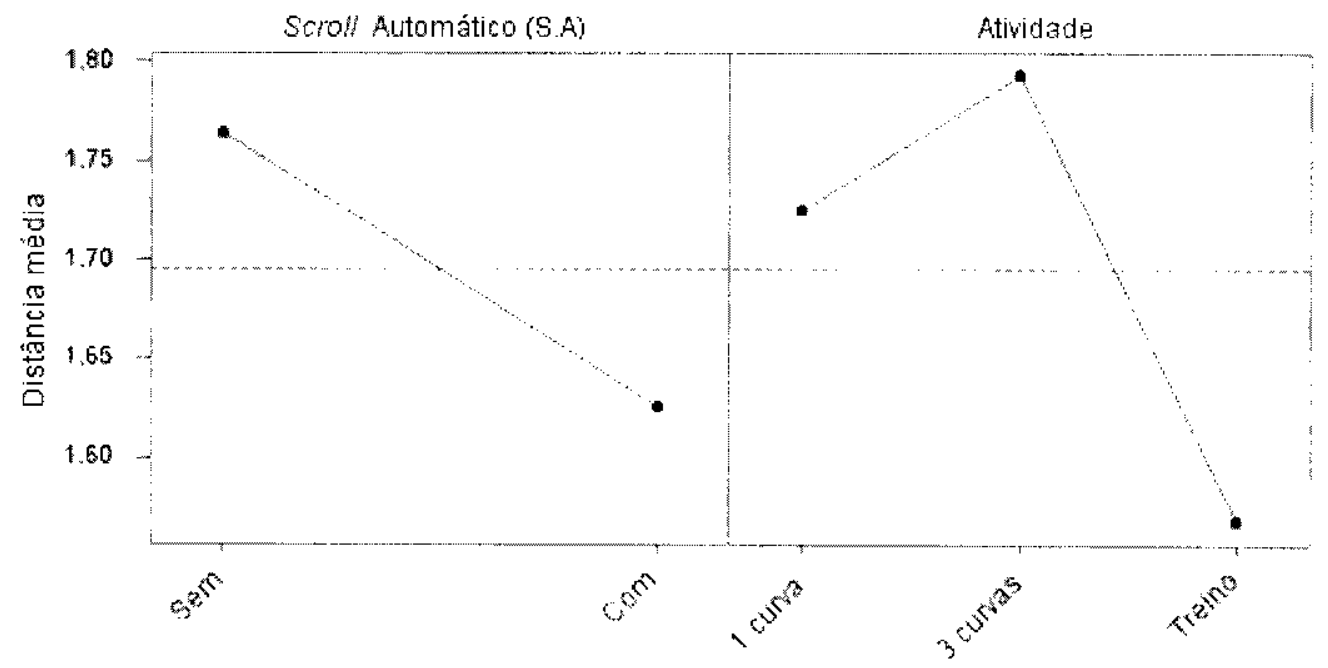

Figura 3.8: Fatores que influenciam a variávcl resposta distância.

Na imagem à esquerda da Figura 3.8, observamos a distância sob influĉncia do tipo de deslocamento. Podemos verificar que, independentemente da ordem ou da experiência do usuário, quando as tarefas são realizadas com deslocamento automático, o usuário tende a fazer um desenho mais preciso sobre os traços preexistentes. Na imagem da direita, observamos que a tarcfa de trcinamento permitiu que os usuários se mantivessem bem próximos dos traços preexistentes. No entanto, para sobrepor as curvas, os usuários não tivcram uma. proximidade tão boa.

Durante a execução do experimento, obscrvamos que alguns usuários cncontraram certa dificuldade durante a tarefa de escrita livre. A Figura 3.9 representa duas imagens obtidas da área virtual. Na imagem da esquerda, notamos que o usuário não conscguiu completar a 
palavra "Natal", parando na letra "t". Isso aconteceu porque o traço vertical dessa letra caiu na região de deslocamento automático. Assim, quando o usuário levantou a caneta da tela na intenção de fazer o segundo traço (horizontal) da letra "t", a tela foi automaticamente deslocada. Antes de perceber o deslocamento, o usuário realizou o traço horizontal na própria região de deslocamento, sendo levado para o início da próxima linha.

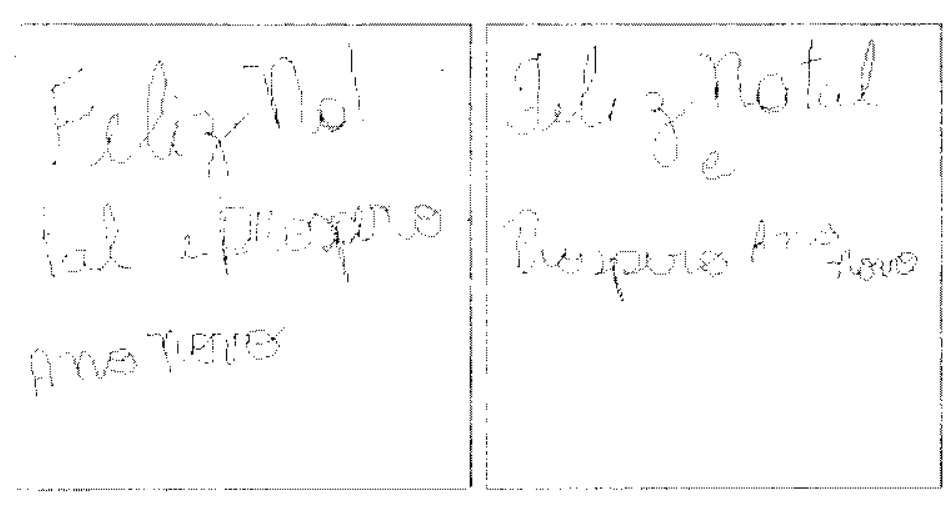

Figura 3.9: Escrita livre com e sen deslocamento automático.

Outro fato interessante aconteceu após a palavra "Próspero". Como o último traço dessa palavra não entrou na região de deslocamento, o usuário forçou uma quebra de linha fazendo um ponto naquela região. Na imagem da dircita, o usuário escreveu utilizando deslocamento manual.

Os resultados do experimento discutido nessa seção foram satisfatórios. A variável resposta tempo foi reduzida com o uso do deslocamento automático e, ainda, observamos que o tipo de deslocamento tcm influência sobre a distância. Porćm, essse cxperimento não avalia a capacidade de orientação espacial do usuário em uma região da qual apenas uma parte é visível. Por isso, conduzimos um segundo experimento cujos resultados são discutidos na próxima seção.

\subsection{Avaliação da Orientação Espacial}

Com a criação de um sistema capaz de simular uma árca virtual maior do que a tela do PDA, surge uma nova questão: como o usuário consegue localizar uma região de interesse dado que ele apcnas enxerga uma porção limitada da área virtual? Para responder a essa pergunta, conduzimos um segundo experimento, no qual cada usuário deve realizar quatro 
tarefas. Cada tarcfa consiste no desenho das doze marcações de um rclógio c dos pontciros de hora e minuto, que devem indicar os horários 3h, 8:40h, 2:45h e $11 \mathrm{~h}$.

Esse teste foi originalmente proposto por Braunberger [Braunberger, 2001] para se obter uma rápida classificação de disfunções cognitivas relacionadas a pacientes com problemas neurológicos e psiquiátricos. Para o nosso caso, csse expcrimento permitirá avaliarmos o tempo e a eficácia dos usuários ao desenharem os horários indicados, de acordo com o planejamento definido na próxima seção.

\subsubsection{Plancjamento}

Esse experimento tem como objctivo avaliar o impacto causado pela utilização do uma área de cscrita virtual que cxtrapola o tamanho da tcla dos PDAs c que, portanto, cxige orientação espacial do usuário. Assim, elaboramos as seguintes questões:

- O usuário consegue se oricntar em uma área da qual enxerga apcnas uma partc?

- As tarefas realizadas pclos usuários na árca virtual são feitas de maneira correta?

- O usuário conscgue diminuir o tempo de realização das tarefas scm alterar a qualidade de sua oricntação espacial?

Para responder a cssas questões, definimos alguns fatores de influência c os níveis que eles podem assumir:

1. Horário -- representa a tarefa quo o usuário realiza no PDA, consistindo no descnho dos seguintes horários: 3h, 8:40h, 2:45h e 11:10h:

2. Sexo -- usuário, masculino ou feminino, que realiza a tarefa.

Definidos os fatores, temos que selecionar as variáveis de resposta. Tendo em mente o objetivo desse experimento, elegemos quatro variáveis:

1. Tempo representa a duração (cm segundos) de uma tarefa. A contagem se inicia quando o usuário encosta a cancta pela primeira vez no PDA c termina após scu último traço; 
2. Distância do centro - é a distância (ern milímetros) do centro do relógio desenhado pelo usuário até o centro do relógio real (base para comparação);

3. Distância das marcas -.. é o somatório das distâncias (crn milímetros) de cada marcação descnhada pclo usuário até a marcação do relógio real;

4. Horário correto diz respeito à correta marcação dos ponteiros do relógio.

\subsubsection{Execução do Experimento}

O experimento foi realizado com 24 usuários, sendo que 12 eram do sexo masculino e 12 do sexo feminino. Para realizar as tarefas, todos usuários descnharam os horários na seguinte ordem: 3h, 8:40h, 2:45h e 11:10h. Além disso, apresentamos um documento impresso a todos usuários a fim de prepará-los para o início da tarefa, conforme ilustrado na Figura 3.10. Na imagem da csquerda apresentamos a configuração inicial de uma tarefa, consistindo de um círculo e das margens da área virtual. Utilizando esse círculo como base, solicitamos que o usuário desenhasse as marcações do relógio (imagem da dircita). A cada nova tarefa, um círculo é exibido conforme a imagem da esquerda.
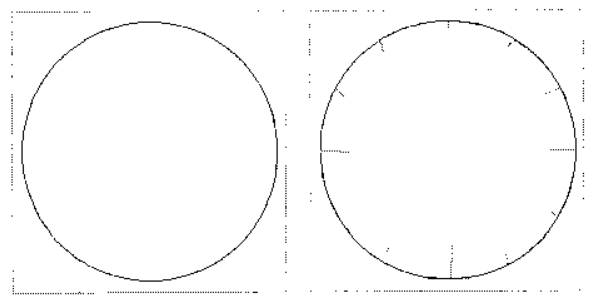

Figura 3.10: Esquerda: configuração inicial do relógio para cada tarefa. Direita: desenho das marcações do relógio.

Para realizar as tarefas, os usuários utilizaram apenas o deslocamento manual (Seção 3.2 ), posicionaram-se na região adequada, marcaram todas as divisõcs do relógio e, em seguida, desenharam os ponteiros. Na Figura 3.11 ilustramos a interface utilizada no experimento. Existe um botão para deslocamento manual (A), um outro botão para desenhos (B) e uma borracha (C). Os outros componentes da interface são análogos aos utilizados no primeiro experimento (Figura 3.1). 


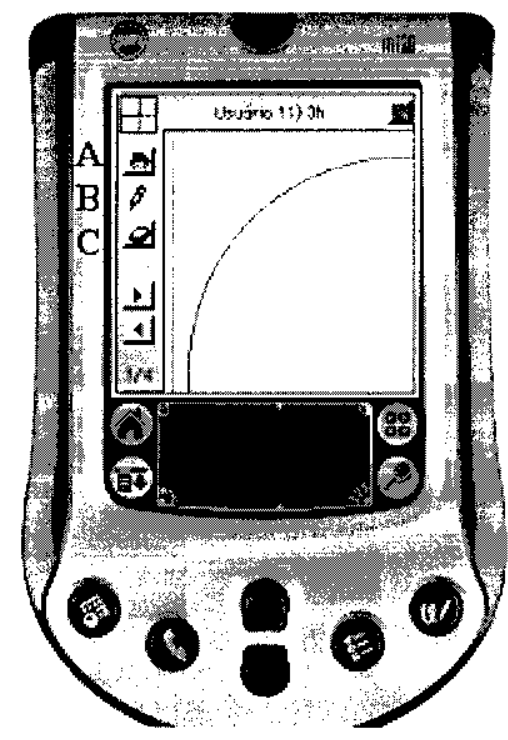

Figura 3.11: Interlace utilizada no experimento, con un botão para deslocamento mantal (A), para desenhos (B) e borracha (C).

\subsubsection{Análise dos Resultados}

Em relação às variáveis de resposta definidas na seção antcrior, o tempo foi medido automaticamente pelo próprio sistema c, para as outras variávcis, fizemos uma verificação manual, sendo que as medidas da distância das marcas e da distância do centro foram realizadas pela mesma pessoa com um único instrumento de medição. Para excmplificar esse processo de modição, utilizamos quatro tarefas realizadas por um determinado usuário (Figura 3.12). Sobre cada um dos relógios feitos por esse usuário, aplicamos um gabarito (Figura 3.13) que possui um contro e as principais marcações de um relógio (divisõos de 5 minutos). Entre essas marcações, criamos subdivisões com linhas pontilhadas (setores), que represcntam faixas de tolerância utilizadas como critério para classificação do horário desenhado.

Dessa forma, dividimos a etapa de avaliação dos relógios em três fases. Primciramente, medimos a distância do centro do relógio desenhado até o centro do relógio do gabarito. Em seguida. fizemos o somatório das distâncias das marcas para cada relógio. Por fim, avaliamos os relógios por horário - primciramente analisamos o horário 3h de todos usuários, depois o horário 8:40h o assim por diante c classificamos os horários cm corretos se todos os critérios abaixo forem satisfeitos: 
1. Os ponteiros do relógio devem estar posicionados nos setores apropriados. Observando os horários 8:40h o 2:45h da Figura 3.13, julgamos que o ponteiro das horas deveria estar desenhado no setor mais próximo das 9 horas e das 3 horas, respectivamente. Como isso não ocorreu, classificamos esses dois horários como incorretos. Verificamos que 58\% dos usuários desenharam incorretamente o horário 8:40h; o mesmo ocorreu com o horário $2: 45 \mathrm{~h}$.

2. O ponteiro das horas deve ser menor que o dos minutos. Apenas $4 \%$ dos usuários não desenharam o relógio de acordo com esse critério;

3. Os ponteiros devem ser desenhados relativamente às marcas do relógio. Esse critério garante que, estando os ponteiros apontando para marcas que foram colocadas incorretamente, o horario seja considerado incorrcto mesmo que os ponteiros estejam nos setores apropriados.

Em seguida, realizamos a análise estatítica de cada variável resposta. Nas próximas seções discutimos os resultados e as conclusões a respcito dessa análise.
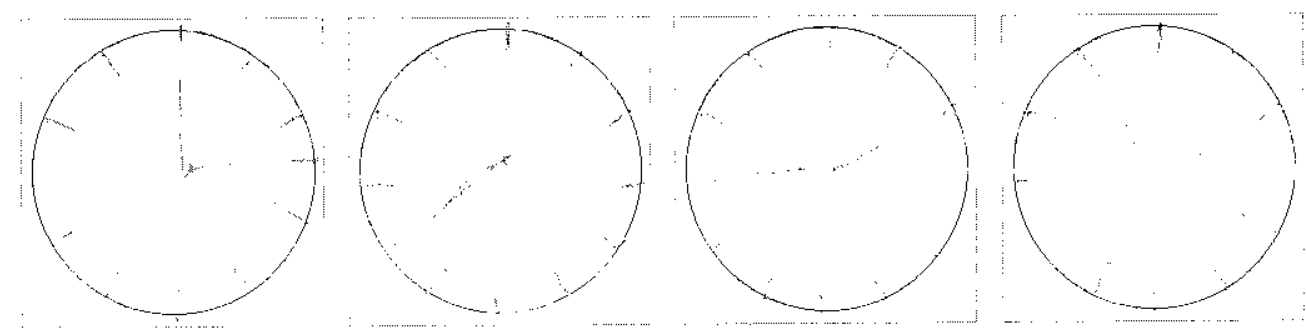

Figura 3.12: Tarefas executadas por um usuário: 3h, 8:40h, 2:45h \& 11:10h.
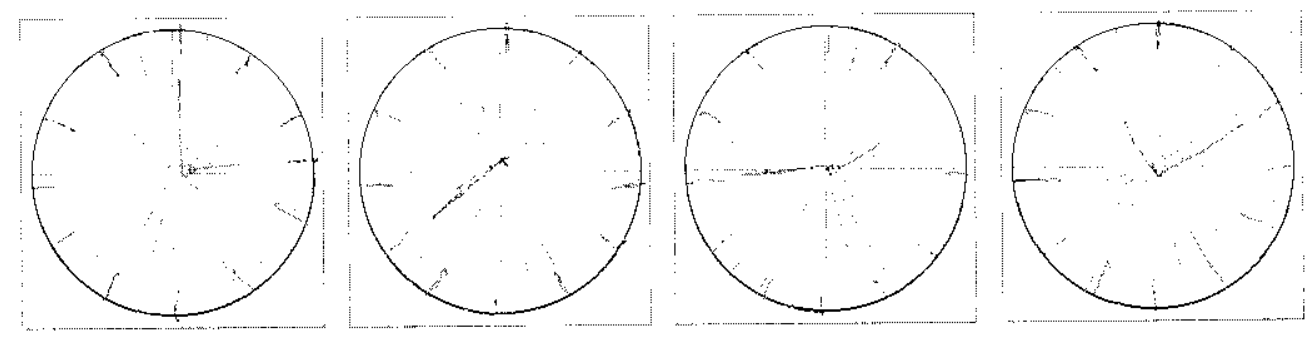

Figura 3.13: Aplicação de um gabarito sobre os relógios da figura anterior. 


\section{Variável Tempo}

Os resultados em relação à variável tempo, resumidos na Figura 3.14, indicam que o tempo para realização da tarefa diminui em relação à ordem de criação dos horários. De acordo com os dados da Tabela $3.1^{3}$, observamos que o P-Valor é menor que 0.05 c, portanto, o tempo é reduzido de maneira significativa para cada novo relógio que o usuário desenha, independentemente do fator sexo.

Tabela 3.1: Análise da variância para o tempo.

\begin{tabular}{lrrrrr}
\hline Source & DF & SS & MS & F & P \\
\hline Sexo & 1 & 1864 & 1864 & 1.20 & 0.277 \\
Horário & 3 & 26202 & 8734 & 5.61 & 0.001 \\
Interaction & 3 & 1829 & 610 & 0.39 & 0.759 \\
Error & 88 & 136925 & 1556 & & \\
Total & 95 & 166820 & & & \\
\end{tabular}

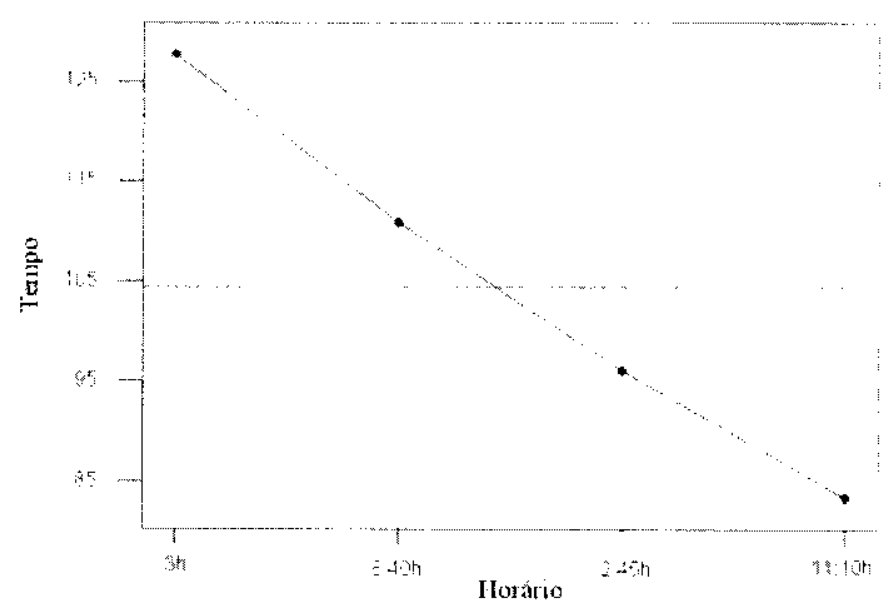

Figura 3.14: Gráfico da ordem de exccução da tarela versus o tempo, em segundos.

\section{Variável Distância das Marcas}

Como podemos observar na Tabela 3.2, os resultados indicam que os fatores horário e sexo não exercem influência sobre a variávcl distância das marcas, uma vez que o P-Valor é maior que 0.05. Com isso, podemos dizer que o usuário não melhora nem piora a qualidade de sua orientação espacial cm relação à criação das marcas a cada novo relógio desenhado.

\footnotetext{
${ }^{3}$ As tabelas apresentadas noste trabalho foram geradas no software de estatística MINTTAB versão 13.0.
} 
Tabela 3.2: Análise dà variância para a distância das marcas.

\begin{tabular}{lrrrrr} 
Source & DF & SS & MS & F & P \\
\hline Sexo & 1 & 100 & 100 & 0.30 & 0.584 \\
Horário & 3 & 1763 & 588 & 1.77 & 0.158 \\
Interactıon & 3 & 594 & 198 & 0.60 & 0.618 \\
Error & 88 & 29160 & 331 & & \\
Total & 95 & 31617 & & & \\
\hline
\end{tabular}

Entretanto, quando analisamos a relação cntre a ordem em que os horários são feitos com o fato de estarem corretos ou não, verificamos que o P-Valor é menor que 0.05 (Tabela 3.3). Dependendo da distância das marcas, podemos dizer que o usuário tem maior probabilidade de acertar o horário à medida que desenha urn novo relógio. Porém, de acordo com a Figura 3.15, esse fato é mais significativo para o horário 3h.

Tabela 3.3: Análise da variância para a distância das marcas sob influência da relação entre a corretitude do horário e a ordem em que são feitos.

\begin{tabular}{lrrrrrr} 
Source & DF & Seq SS & Adj SS & Adj MS & F & P \\
\hline Correto & 1 & 3590.6 & 6691.7 & 6691.7 & 28.39 & 0.000 \\
Horário & 3 & 3941.9 & 7221.1 & 2407.0 & 10.21 & 0.000 \\
Correto*Horário & 3 & 3340.2 & 3340.2 & 1113.4 & 4.72 & 0.004 \\
Error & 88 & 20744.3 & 20744.3 & 235.7 & & \\
Total & 95 & 31617.0 & & & & \\
\hline
\end{tabular}

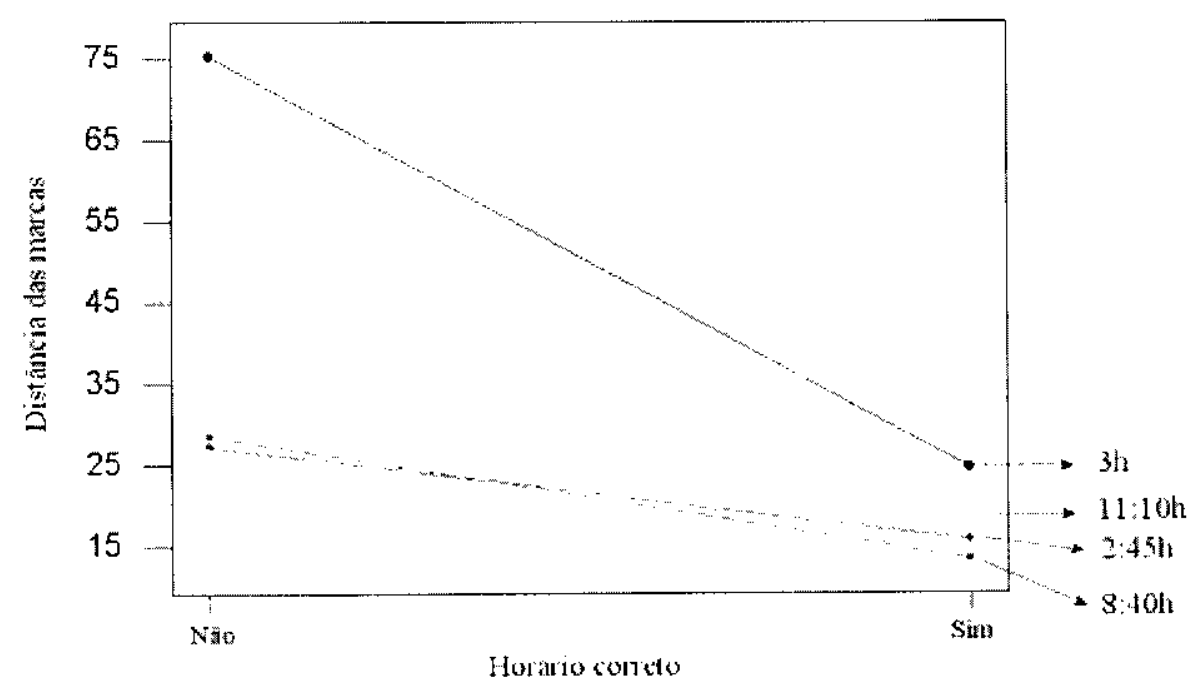

Figura 3.15: Gráfico da distância das marcas, em milímetros, sob influência dos horários e do horário correto. 


\section{Variável Distância do Centro}

Conforme a Tabcla 3.4, observamos que o fator sexo tem influência significativa sobre a distância do centro (P-Valor $<=0.05$ ). Usuários do sexo masculino marcaram o centro do relógio mais próximo do centro real do que usuários do sexo feminino (Figura 3.16). Por outro lado, a ordern em que os horários são fcitos não é significativa, o que reafirma a conclusão da scção anterior de que o usuário não altera a qualidade de sua orientação espacial a cada novo relógio desenhado, em relação à marcação do centro.

Tabela 3.4: Análise da variância para a distância do centro.

\begin{tabular}{lrrrrr} 
Source & DF & SS & MS & F & P \\
\hline Sexo & 1 & 41.34 & 41.34 & 11.47 & 0.001 \\
Horário & 3 & 14.95 & 4.98 & 1.38 & 0.253 \\
Interaction & 3 & 6.03 & 2.01 & 0.56 & 0.644 \\
Error & 88 & 317.08 & 3.60 & & \\
Total & 95 & 379.41 & & & \\
\hline
\end{tabular}

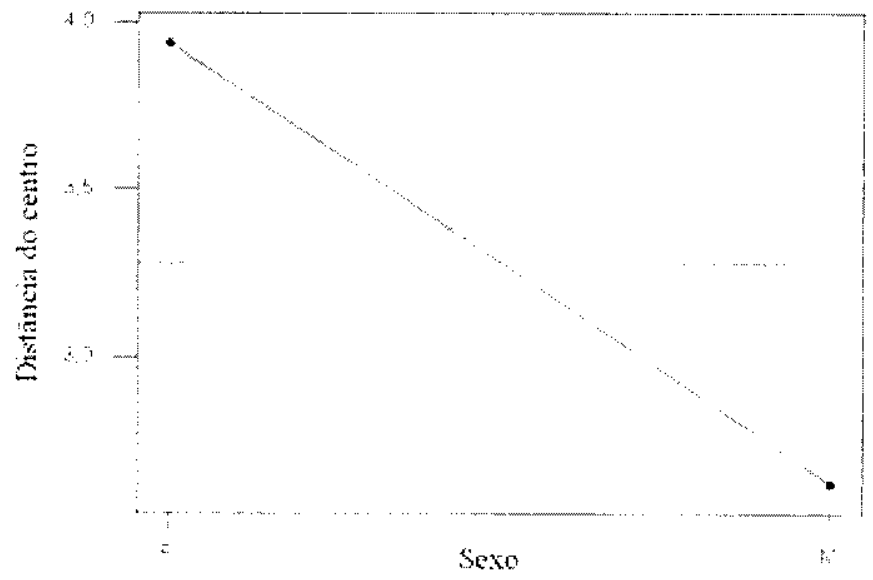

Figura 3.16: Gráfico do sexo vcrsus a distância do centro, em milímetros.

\section{Variável Horário Correto}

De acordo com a Tabela 3.5, podemos observar que o horário correto não é influenciado significativamente pelo fator sexo (linha 3, P-Valor > 0.05). Porém, o valor $1.61(>1$ ) da coluna Odds Ratio indica que usuários do sexo masculino têm maior probabilidade do desenhar tum horário correto do que usuários do sexo feminino. 
Em relação ao fator horário, podemos verificar que a probabilidade de acerto dos horários 2:45h (linha 5) e 8:40h (linha 7) é menor que o acerto do horário 11:10h (Odds Ratio $=0.10$ ). Além disso, a probabilidade de acerto dos horários 3h e 11:10h ć a mesma.

T'abela 3.5: Regressão logística.

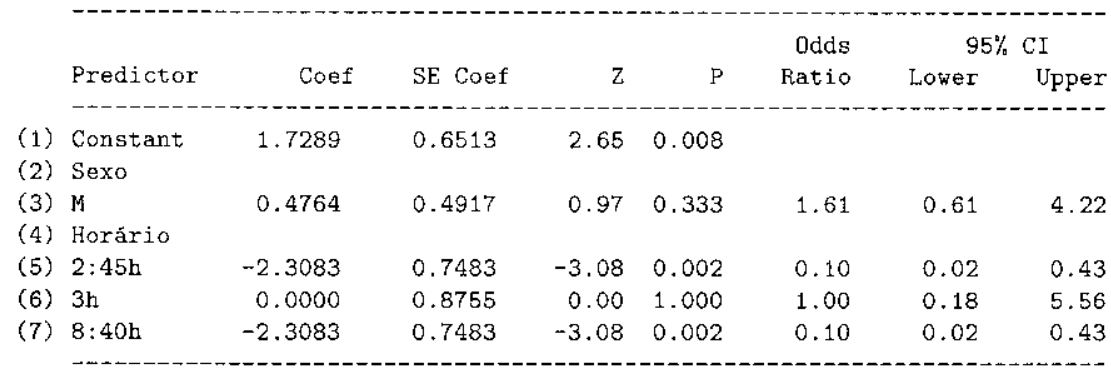

\subsection{Considerações Finais}

Os resultados obtidos com a aplicação do primeiro experimento indicaram que o mecanismo de deslocamento automático foi satislatório tanto em relação ao tempo de conclusão das tarefas quanto ao fator distância. Portanto, concluímos que esse mecanismo pode ser uma boa alternativa para o deslocamento manual durante anotaçoes por escrito, embora os dois possam coexistir em uma aplicação. Para relatar csse expcrimento, em Janeiro de 2004 submeternos um artigo para a revista Interfaces do British HCI Group ${ }^{4}$, intitulado Automatic scroll supporting input in PDAs.

Motivados com os resultados do primeiro experimento, conduzimos um segundo experimento para investigar o impacto causado pela utilização de uma área virtual que cxtrapola o tamanho da tela dos PDAs. As tarefas utilizadas foram adaptadas de um teste para classificação de pacientes com problemas neurológicos e consistiam no desenho de quatro relógios com seus ponteiros e suas marcaçõcs. Para realizar as tarefas, os usuários utilizaram apenas o deslocamento manual, visto que os desenhos não estavam relacionados com a escrita de anotações. Por fim, analisamos os resultados de 24 usuários o concluímos que eles conseguiram reduzir significativamente o tempo da tarcfa a cada novo relógio desenhado, sern que a qua-

\footnotetext{
${ }^{4}$ http://www.bes-hei.org.uk/index.html
} 
lidade de sua orientação espacial fosse alterada. Essc fato foi vcrificado independentemente do sexo do usuário.

O mecanismo que cxplora a utilização de uma área virtual maior que a tela do PDA c pcrmite a rolagem automática de textos foi incorporado a um sistema para suportar a realização do anotaçõos $\mathrm{cm}$ ambicntcs educacionais. As caractcrísticas desse sistema, suas relações com aplicações de captura e acesso e os aspectos de integração com o Projcto InCASERVE são discutidos no próximo capítulo. 


\section{Capítulo 4}

\section{Anotações em PDAs Integradas ao Projeto InCA-SERVE}

\subsection{Considerações Iniciais}

O grande avanço da tecnologia na área da computação levou alguns pesquisadores a investigarem o relacionamento entre dispositivos como PDAs c SDGs (Single Display Groupware, por exemplo, uma lousa eletrônica) e a área de trabalho cooperativo suportado por computador (CSCW - Computer Supported Cooperative Work). De acordo com Grecnberg et al. [Greenberg et al., 1999], o que torna esses dispositivos interessantes para a área do CSCW ć que ambos podem ser vistos como instrumcntos de informação, isto é, são capazes de trocar informações cntre si. Grecnberg et al. estavam interessados em explorar como as pessoas transferem seus artefatos pessoais (criados em scus PDAs) para o domínio público (manipulados em SDGs) e vice-versa. Além disso, esses pesquisadores levantaram várias questões de projeto relacionadas à troca de informações, incluindo diferenças entre dispositivos c a distinção entre artefatos públicos e privados, e destacaram as dificuldades dos usuários com a entrada de texto.

Waycott e Hulme [Waycott c Kukulska-Hulme, 2003] estão entre os autores que relatam que os PDAs não são apropriados para entrada de texto. Tipicamente, os usuários utilizam 
um teclado na própria tcla do dispositivo ou cscrcvem sobre a tela em uma região especialmente designada para reconhecimento de caracteres, um processo lento e muitas vczes impreciso. Por outro lado, durante os estudos de avaliação sobre as mudanças que ocorrem quando estudantes usam PDAs para ler e interagir com materiais de cursos, Waycott e Hulme observaram que esses estudantes se sentiram beneficiados ao armazenar anotações eletronicamente. Com os dispositivos portáteis, os estudantes percebcram que teriam suporte às atividades de ensino, sendo possível resumir materiais de cursos c manter suas anotações melhor organizadas.

Baseados nessas idćias, buscamos elaborar um sistema que suporte as atividades de um usuário em particular c de um grupo de usuários de modo geral. No primeiro caso, o usuário é capaz de armazenar, recuperar c fazer ligações entre anotações, bem como agrupá-las de acordo com o curso c aula desejados. Para o segundo caso, o usuário pode compartilhar suas anotações com os membros de seu grupo, utilizando, como meio de comunicação, uma lousa eletrônica. Ao tornar públicas as anotações privadas, toda a informação trocada é armazenada $\mathrm{cm}$ um repositório comum e acessível pela Web.

Este capítulo apresenta os aspectos de integração de um sistema de anotações com o Projeto InCA-SERVE. Trata-se do sistema aNOTE, que foi construído como uma camada acima da infra-cstrutura de software INCA (Scção 2.4) e que, portanto, utiliza seus módulos c interfaces para facilitar a troca de anotações através da rede. Também são discutidos os aspectos relacionados ao armazenamento de anotações utilizando o serviço StRES (Seção 2.4).

Na Scção 4.2 fazemos uma descrição do aNOTE, abordando as questõcs de interface, cenários de uso e os scrviços implementados como parte do sistema. Na Seção 1.3 apresentamos os esquemas de armazenamento de anotações utilizados por esse sistema. Em seguida, na Scção 1.1, mostramos como é feito o acesso às informações armazenadas e, finalmente, na Scção 4.j apresentamos as considerações finais a respeito do sistema c de sua integração ao Projeto InCA-SERVE. 


\subsection{Apresentação do Sistema aNOTE}

A idéia central do Sistema aNOTE é dar suporte à realização de anotações individuais em ambientes de sala de aula e ao compartilhamento das mesmas. Portanto, para melhor compreensão, dividimos o sistema em três serviços, cujo esquema básico de comunicação está ilustrado na Figura 4.1.

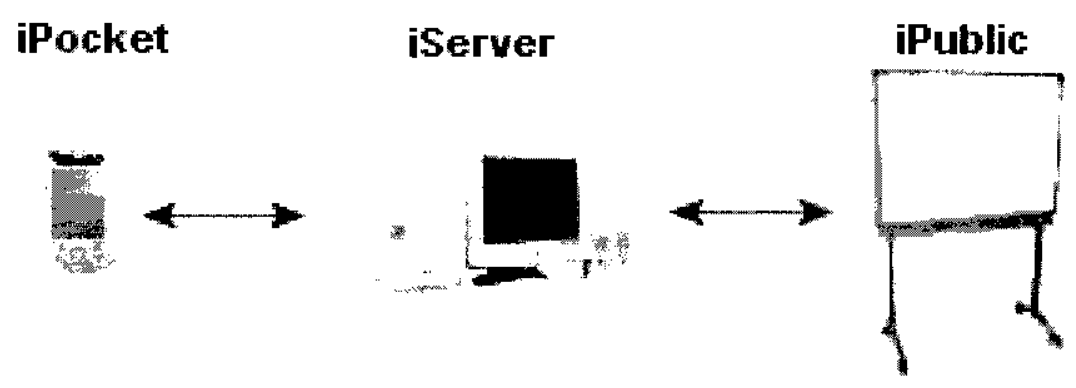

Figura 4.1: Comunicação entre os três serviços do Sistema aNOTE: iPocket, iServer e iPublic.

O primeiro serviço é chamado iPocket e seu ambiente de execução é em PDAs. Esse scrviço contém ferramentas de controle de anotações, permitindo que a escrita seja feita de maneira livre. O mecanismo de rolagem de textos é o descrito na Seção 3.2. Na Figura 1.2 apresentamos as principais tclas do iPocket. Na imagem da esquerda observamos a seleção de um curso e de uma aula daquele curso e a identificação do usuário. A próxima tcla se refere à criação de slides imagem do centro. O usuário pode criar um slide em branco ou reusar algum que já tcnha sido armazenado em scu próprio dispositivo referente a uma determinada aula. Cada slide é acompanhado por um conjunto de informações, incluindo o título, a prioridade (ou ranking), a data e a hora de criação da anotação. Na imagem da dircita podemos observar a região de escrita, uma caixa de seleção para o ranking, o título, o horário de criação da anotação o os botões de deslocamento manual (A), navegação (B e D), criação de novo slide (C), mudança de cor (E), criação de links (F) e exclusão de slides $(\mathrm{G})$.

Para criarmos um link cntre duas anotações, por excmplo, acionamos o botão apropriado (F), marcamos a região de interesse na área de escrita e selecionamos o slide destino na janela exibida (Figura 4.3 da esquerda). A palavra "XML", por exemplo, representa um 

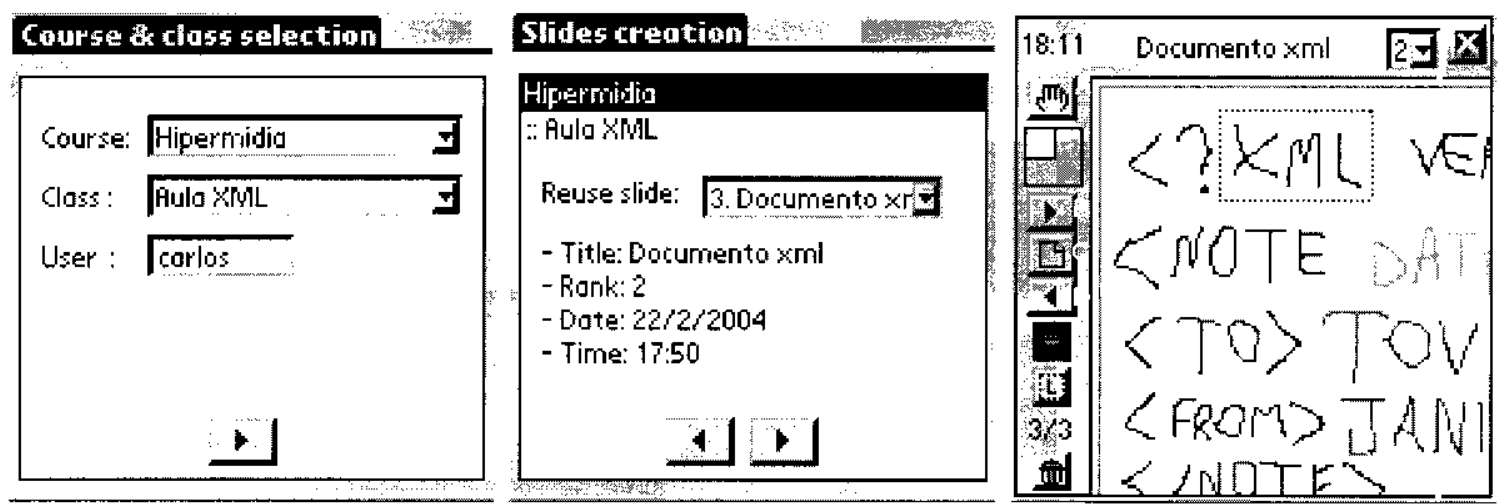

Figura 4.2: Telas do iPocket. Esquerda: selcção do curso e da aula. Centro: seleção de um slide já existente. Direita: ferramentas e região de escrita de anotaçōes.

link para o primeiro slide, entitulado "Conceito XML". Basta clicarmos dentro da região do ligação para accssarmos o slide destino.
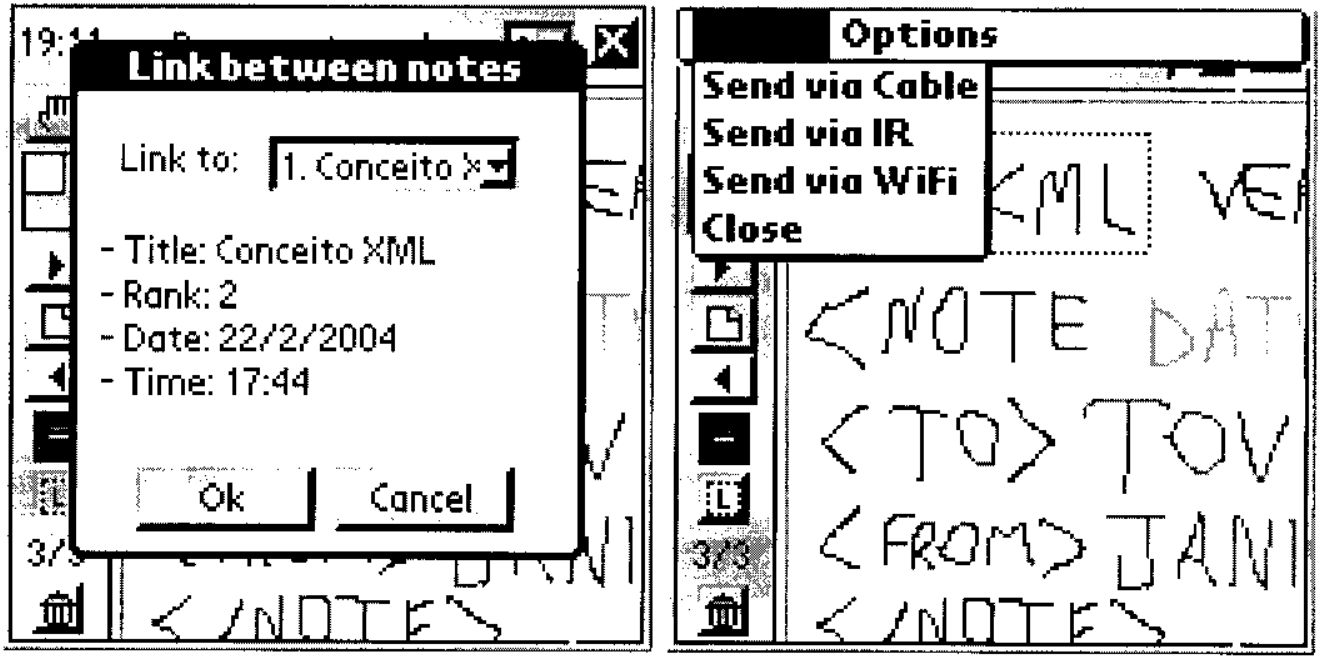

Figura 4.3: Telas do iPocket. Esquerda: criação de um link para o primeiro slide. Direita: exibição das opções de envio da anotação: por cabo, infravcrmelho ou rede wireless.

Para tornar pública uma anotação, o usuário deve utilizar o menu c sclecionar o tipo de transferência descjado (Figura 4.3, direita). As opções são o envio por cabo scrial, infravcrmelho ou rede wireless. No primeiro caso, o PDA deve estar associado a um PC através de uma base de encaixe do próprio dispositivo. Com o infravermelho, usuários podem cnviar suas anotações a uma distância de, aproximadamente, dois metros do receptor que está conectado ao PC. Através da rede wireless, todo o espaço dentro de uma sala de aula, por exemplo, pode ser utilizado para o envio de anotações, desde que haja um ponto de 
acesso à rede nessa sala. Validamos os dois primeiros casos com PDAs da plataforma Palm Computing $^{1}$, c o terceiro caso foi verificado com iPAQ's modelo H5500, da Hewlett-Packard [iPAQ, 2003]. No restante deste trabalho, utilizaremos o cenário da rede wireless, tal como ilustrado na Figura 4.4.

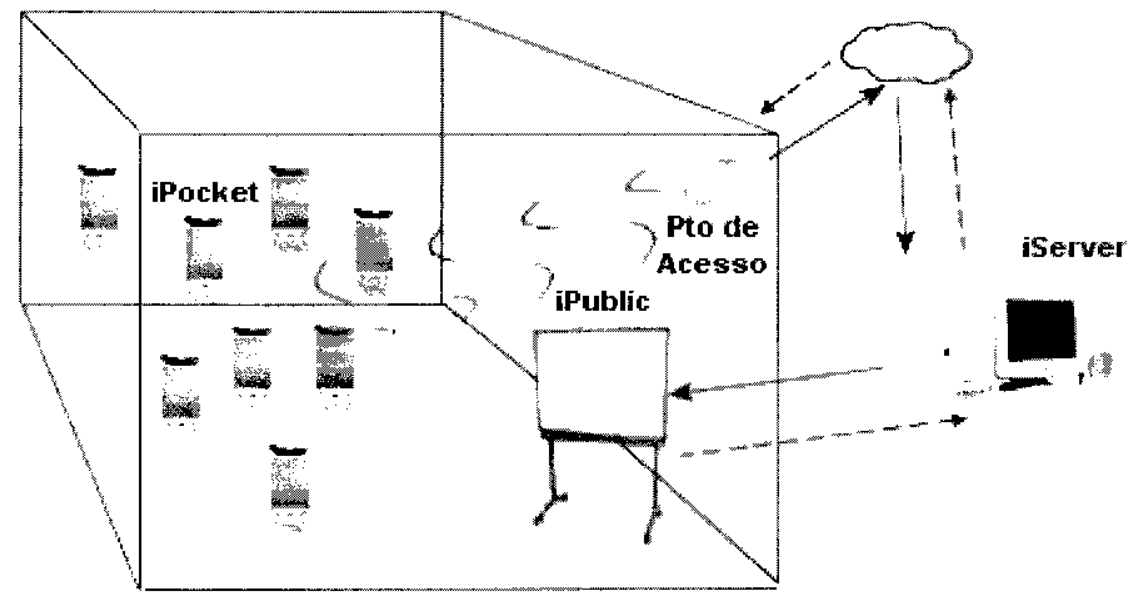

Figura 4.4: Conário de uso do aNOTE utilizando um ponto de acesso da rede wireless. Anotações geradas nos PDAs são enviadas pela rede (representada pela nuvem) para a lousa e vice-versa.

Após a solicitação de envio pelo usuário, as anotações são apresentadas ao segundo serviço, chamado iServer, que está em execução em um determinado PC. O iServer atua como um empacotador, lendo os dados provenientes do iPocket e criando pacotes de informação segundo o formato definido pela infra-estrutura de software INCA (Scção 2.4). Nesse momento, os pacotes são capturados e direcionados pela INCA até o destino apropriado, quando, então, ocorre a fasc de acesso. O scrviço responsável por desempacotar as informações c acessar o conteúdo dos dados ć chamado iPublic. Esse serviço está em execução na lousa eletrônica ${ }^{2}$ e mantém uma lista dos usuários que enviaram suas anotações. A cada usuário está associada uma janela de anotação pública (ou mini-lousa), cujo tamanho corresponde à área virtual criada pelo iPocket (Seção 3.2). Uma lista de slides é mantida para cada mini-lousa, de tal forma que todas as anotações cnviadas pelos usuários possam scr acessadas a partir da lousa eletrônica. O iPublic também permite que as informações fluam no sentido oposto. Nesse caso, esse serviço se responsabiliza por capturar e empacotar as anotações feitas diretamente sobre uma das mini-lousas presentes na lousa eletrônica. Os pacotes são transmitidos

\footnotetext{
${ }^{1}$ http://www.palm.com

${ }^{2}$ A lousa eletrônica está acoplada a um computador convencional, ligado em rede.
} 
através da INCA até o iServer que, por sua vez, realiza o desempacotamento, repassando as informações para o respectivo PDA.

Na Figura 4.5 apresentamos um exemplo de uso do sistema aNOTE. O PDA existente na figura ilustra o fato de que as anotações feitas nesse dispositivo são apresentadas na lousa eletrônica. Na figura, as duas janelas com os títulos "carlos" e "billy" indicam que existem dois usuários na sala de anotações (Room Notes ó a janela principal do iPublic) com anotaçõos submetidas. Esses usuários estão participando de uma sessão de captura (aula), cujos slides são apresentados ao fundo pelo Sistema iClass (Scção 2.4), utilizando o componente de whiteboard da XINCA. Na interface da mini-lousa existem botões de navegação e um botão para criação de novos slides. Quando executadas, cada uma dessas ações é refletida instantaneamente no respectivo PDA.
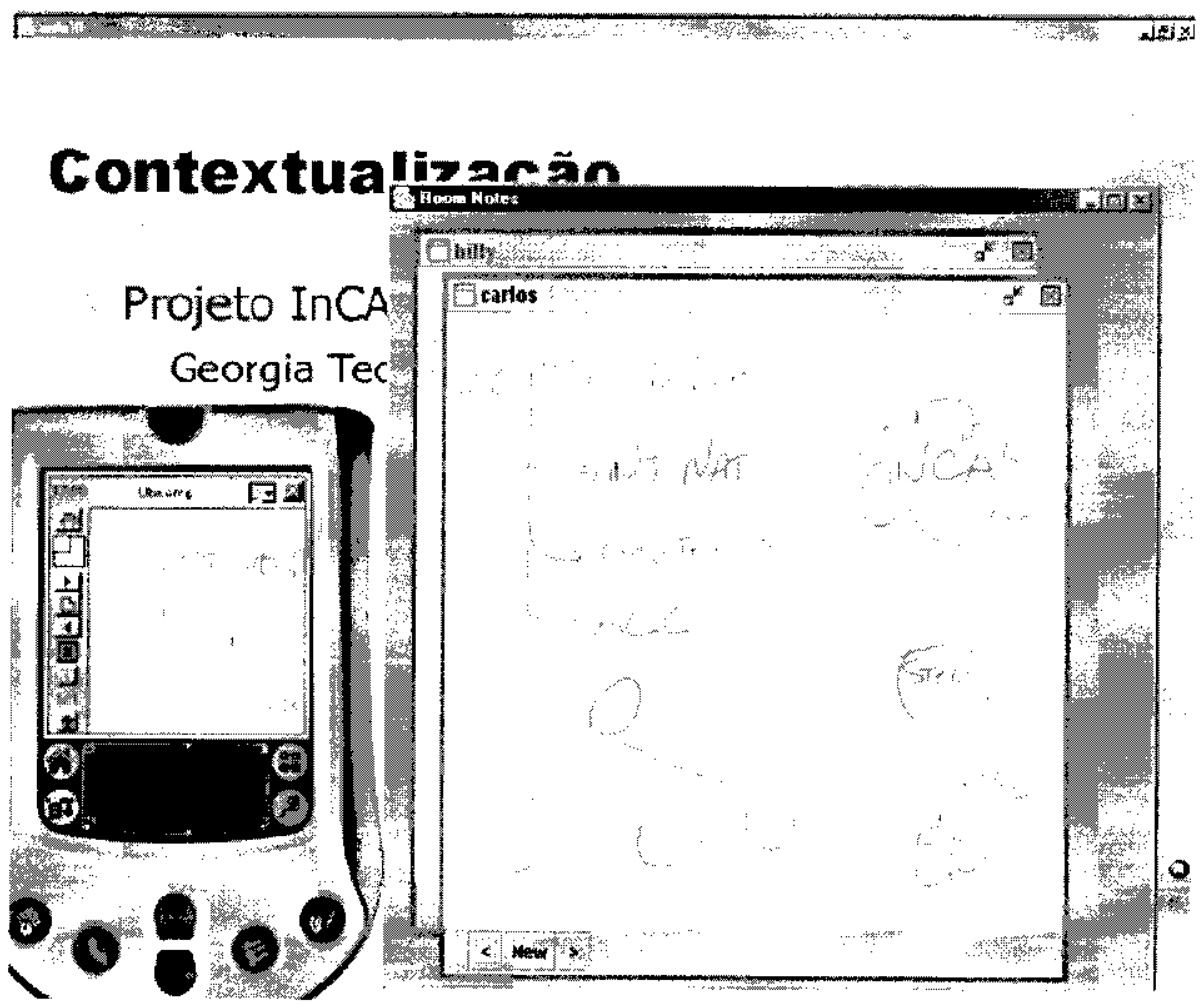

Figura 4.5: Ilustração dos scrviços iPocket e iServer com dois usuários ("carlos" e "billy") submetendo suas anotações.

Para o desenvolvimento dos scrviços citados, utilizamos a linguagem Java, sendo que o ambiente de execução do iPocket é a máquina virtual do SupcrWaba ${ }^{3}$. Além de ter seu

\footnotetext{
${ }^{3}$ http://www.superwaba.com.br
} 
código aberto, essa plataforma possibilita, em princípio, que as aplicações sejam executadas em vários sistemas operacionais, incluindo Palm OS, Windows CE/98/ME/2000/NT/XP e Mac OS-X.

\subsection{Armazenamento das Anotações}

Para que as anotações possam ser acessadas depois de concluída a sessão, seja pelo PDA ou pela Web, precisamos armazená-las de acordo com duas características. 'Todas as anotações privadas devem ser armazcnadas no PDA o as anotações que se tornaram públicas devem ser armazenadas pelo StRES (Seção 2.4) em una base de dados accssível pela Web. Nas próximas seções, abordamos esses dois aspectos do armazenamento, o privado e o público.

\subsubsection{Armazenamento Privado}

A plataforma de programação que utilizamos, o SuperWaba, possui um pacote de classes relacionadas com o tratamento de tarefas de entrada e saída (waba.io). Uma das classes mais importantes desse pacote é chamada Catalog, que permite o armazenamento de informações na base de dados do dispositivo [Hazan, 2003]. Catalog é o tipo mais rudimentar de baso de dados, consistindo en um vetor (array) de registros. Cada registro pode ter tamanho diferente e o númcro máximo de registros é limitado a 32767.

A dificuldade de se trabalhar com o Catalog é que não existem definições de tabela nem do campos. Do ponto de vista do sistema operacional, o conteúdo de um registro são apenas dados primitivos. Abaixo, ilustramos como os dados de um registro podem ser acessados a partir de um Catalog:

1. Abrir o Catalog.

2. Ajustar o cursor interno na posição do registro desejado.

3. Armazenar ou recuperar dados do registro corrente;

Essas operações avançam o ponteiro existente dentro do registro.

4. Ir para (2), ou fechar o Catalog.

Para facilitar o desenvolvimento de aplicações que utilizam a classe Catalog, criamos 
uma classe chamada PockctDataBase, que abstrai a manipulação do armazcnamento e da recuperação de dados de um PDA. Os principais métodos e atributos dessa classe estão ilustrados na Figura 4.6. A leitura de um registro é feita pelo método readRecord(), responsável por retornar todos os dados presentes naquele registro. A escrita é realizada pelo método writeRccord(), cujo parâmetro permite o armazenamento de um conjunto de dados que constituirão um novo registro.

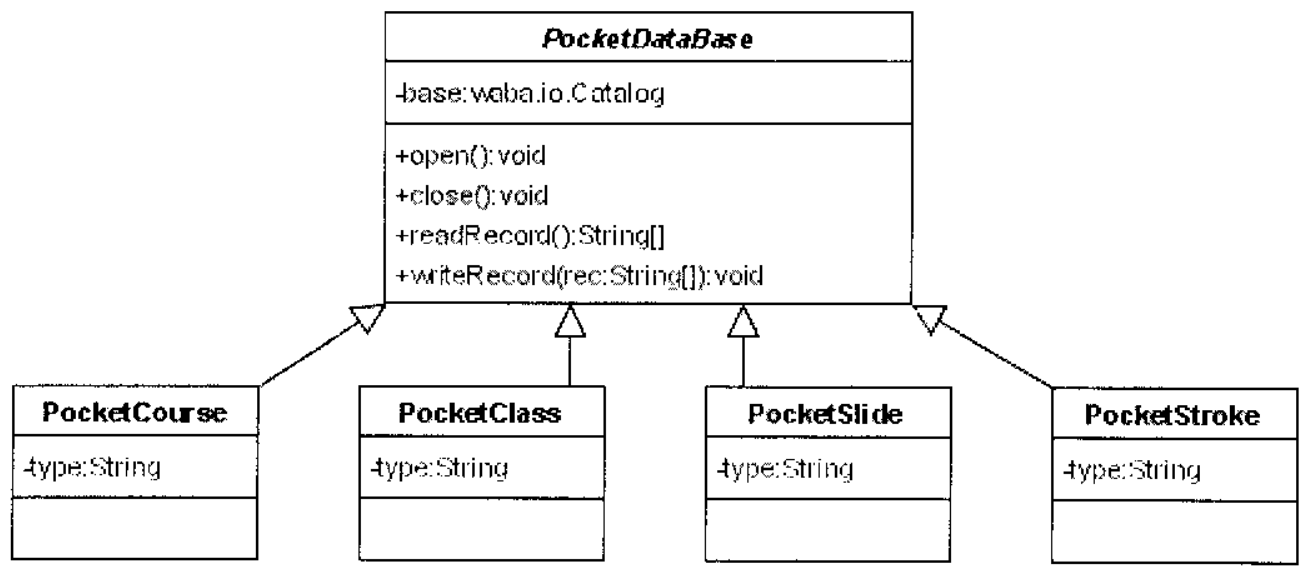

Figura 4.6: Diagrama LML de classes para o armazenamento de dados.

Ainda na Figura 4.6, ilustramos quatro classes que fazcm parte de nossa aplicação. Como estamos interessados em armazenar informações sobre o curso, aula, slides e traços (strokes) que constituem esses slides, criamos as respectivas classes para tratar esses conjuntos de dados. Cada um dos objetos possui um atributo (type) que identifica o tipo de Catalog que será utilizado por aquele objeto. Nesse sentido, podernos dizer que um Catalog seria uma tabela em uma base de dados relacional, os registros seriam as linhas da tabela e os campos desses registros scriam os atributos da tabcla.

As classes PocketCourse, PocketClass, PocketSlide e PocketStroke manipulam os respectivos Catalogs, tal como ilustrado na. Figura 4.7. Para o curso, por excmplo, existem dois registros com dois campos cada um. O primeiro campo representa o nome do curso e o segundo. uma lista de índices para as aulas relacionadas ao curso. Os registros de aula que estão nas posições 0.1 c 2 pertencem ao curso 0. A aula cujo registro está na posição 0 possui dois slides com informações sobre o título, prioridade, data e hora da anotação, coordenada e links presentes naquele slide. Na mesma posição do slide, encontram-se os dados 
dos strokes, que representam as anotações propriamente ditas.

\section{Catalogs}

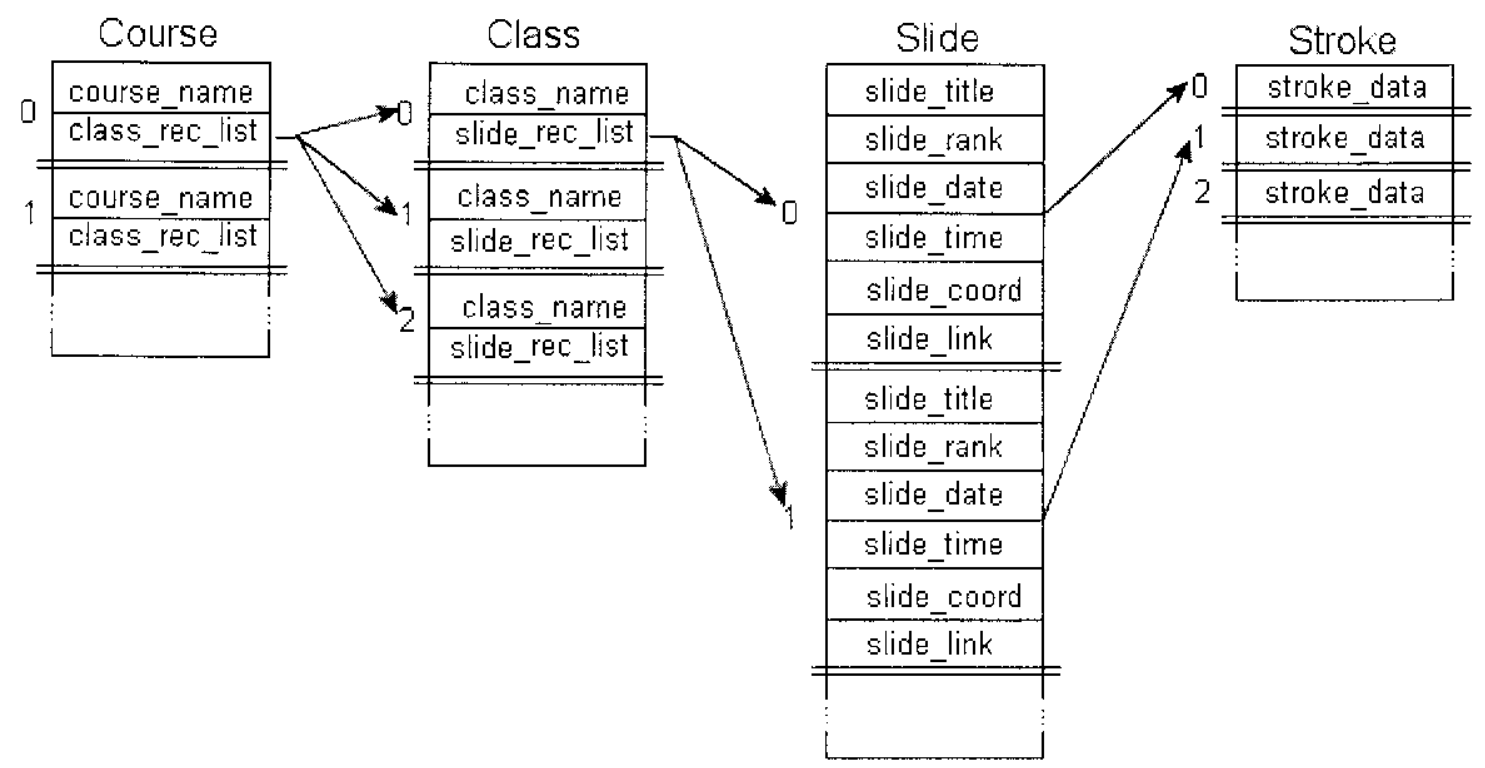

Figura 4.7: Ilustração dos Catalogs responsáveis pelo armazenamento dos dados refentes ao curso, aula, slides e strokes.

A partir dessa estrutura de armazcnamento e recuperação de anotações em PDAs, podemos especificar um cenário em que todas as informações de curso e aula são carregadas, por exemplo, nos dispositivos de alunos no início de cada semestre. Em salas de aula que possucm lousa cletrônica, é possível apoiar uma maior interação entre professor e alunos. Nesse caso, além do armazenamento local das anotações, devemos prover suporte para o armazenamento das anotações que se tornaram públicas, de tal forma que consultas possam ser feitas ao material gerado após o término da aula. Esse é o assunto da próxima seção.

\subsubsection{Armazenamento Público}

Com o intuito de possibilitar o acesso às anotações públicas após o término de uma sessão, utilizamos os serviços fornecidos pelo StRES para armazenanento da informação capturada. Na Figura 4.8 apresentamos uma visão geral do esquema de armazenamento do Sistema aNOTE. Nessa figura, observamos a presença de módulos responsáveis por capturar (C) informações de PDAs ${ }^{1}$ e eventuais entradas de dados na própria sala de anotações. Anotações

\footnotetext{
${ }^{4}$ Para simplificar, ostamos ilustrando módulos de captura e acesso diretamente associados a PDAs.
} 
realizadas dirctamente sobre a mini-lousa são enviadas tanto para o módulo de acesso (A) associado ao PDA quanto para o módulo associado ao StRES. Dessa forma, ao final de uma scssão (aula, por exemplo) as anotaçõcs são armazenadas como imagens e um documento XML que representa aquela sessão é gerado e armazenado em uma base de dados pelo StRES.

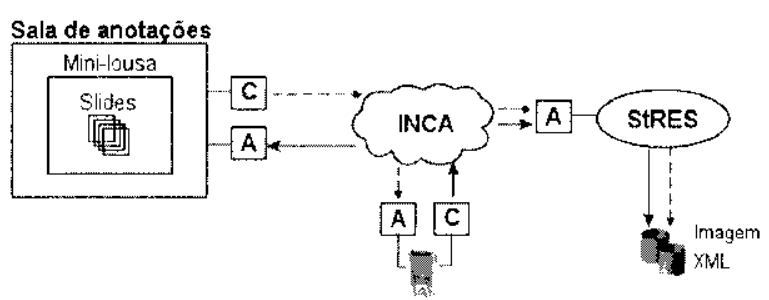

Figura 4.8: Ilustração do processo de armazenamento do anotaçõcs.

O StRES possui um objeto chamado Transduccr que instancia módulos de acesso do aNOTE. Portanto, o Transducer recebe dados dos módulos de captura presentes nos serviços iServer e iPublic com o objetivo de gerar um documento XML representativo da sessão. Na tentativa de organizar as informações produzidas por csses serviços, nós especificamos um documento DTD 5 para o Sistema aNOTE a fim de podermos estruturar os dados capturados em informações mais comprcensíveis e controláveis.

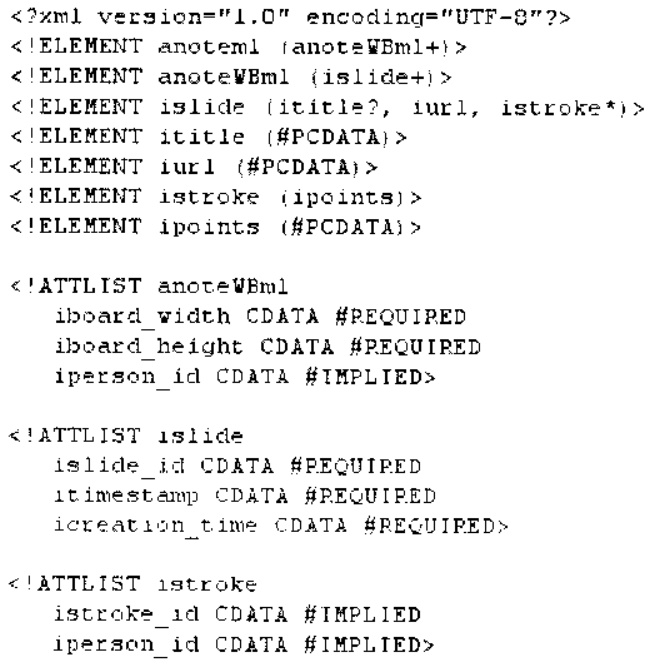

Figura 4.9: Documonto DTD para uma sessão de anotaçōes.

Na Figura 4.9 ilustramos esse DTD. O elemento anoteml reprosenta a sala de anotaçoes e, portanto, pode conter uma ou mais mini-lousas (anoteWBml). Uma mini-lousa é composta 
por um ou mais elementos islide, cada um dos quais possui um título (ititle), um caminho (iurl) e um conjunto de traços (istroke). Um ou mais pontos (ipoints) constituem um traço. O elemento anoteWBml possui atributos relacionados à dimensão, como largura e altura, e à identificação do usuário relacionado. Os elementos islide e istroke têm um identificador como atributo, sendo que o clemento istroke tem a informação de quem (iperson-id) realizou o traçado. Além disso, cada islide possui a data e a hora em que foi criado e um marcador (timestamp) relativo ao início da sessão.

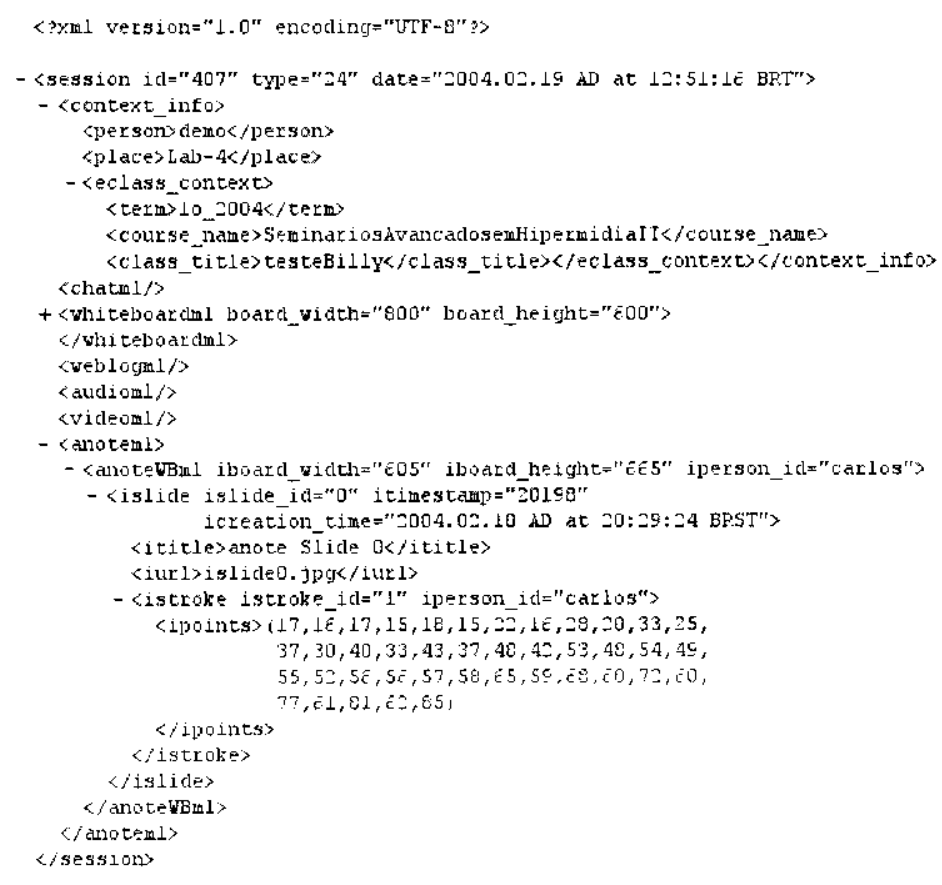

Figura 4.10: Documento XML.

Na Figura 4.10 apresentamos um documento XML com destaque para a sessão de anotações (anoteml). Observamos a existência de um elemento anoteWBml, que possui um slide com informações sobre o título, caminho e conjunto de pontos. Como uma sessão de anotações faz parte de uma sessão mais genérica, podemos observar, no início do documento XML, elementos como informações de contexto, whiteboard, áudio, vídeo e chat, todos pertencentes ao elemento session. Portanto, o DTD de uma sessão de captura deve conter esses elementos, de acordo com a Figura 4.11. Podemos observar que uma sessão (clemento session) deve possuir informaçoes de contexto (por exemplo pessoa, lugar, nome do curso e título da aula) e pode conter uma sessão de anotações do aNOTE (clemento anoteml). 


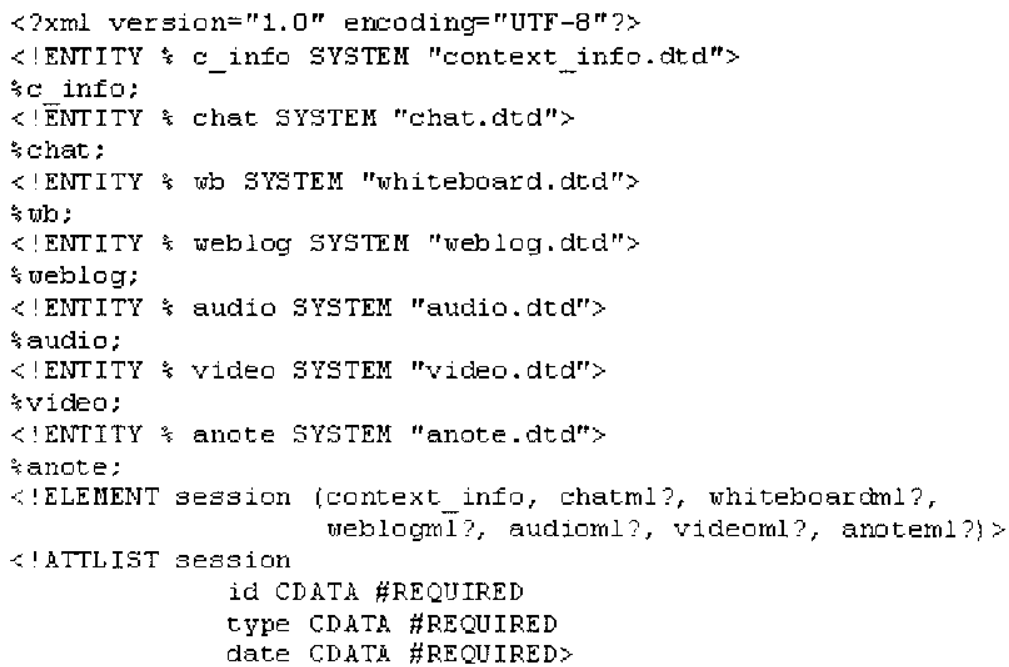

Figura 4.11: Documento DTD para uma sessão.

Para derivarmos classes Java a partir dos elementos c atributos presentes no DTD da scssão de anotações, utilizamos um mecanismo de ligação (binding) de dados. Esse mecanismo permite que aplicações clientc-scrvidor definam objetos responsáveis por manipular e trocar a informação capturada. Trata-se da API JAXB (Java Architecture for XML Binding) ${ }^{6}$, fornecida pela Sun Microsystcms. Essa API possui um compilador que transforma um documento DTD em objetos Java prontos para serem utilizados cm uma aplicação. Por exemplo, uma das classes do scrviço iPublic trabalha com um objeto istroke, criado a partir da compilação do DTD exibido na. Figura 1.9. No momento que uma anotação chega na sala de anotaçôes, preenchomos esse objeto com os pontos que formam os strokes e com a identificação do usuário que enviou a anotação. Seguindo esse princípio, conscguimos montar os objetos islide, anoteWBml e anoteml que, por sua vez, é manipulado pelo objeto da sessão session.

Finalmente, quando uma scssão é enccrada, o StRES, através do objeto Transducer, utiliza mótodos da API JAXB para transformar todos os objetos Java referentes à sessão cm um documento XML, segundo um processo conhecido por marshalling. O documento XML ilustrado na Figura 4.10 foi gcrado dessa forma. Com isso, podemos armazenar documentos relacionados a scssõcs de captura, juntamente com suas mídias associadas, cm uma base

\footnotetext{
${ }^{6}$ hittp: / /java.sun.com/xml/jaxl)
} 
de dados X.ML … o Xindice ${ }^{\top}$. Issso permite a realização de consultas c a apresentação do material capturado em diversos formatos. Esse assunto scrá tratado com mais detalhes na próxima seção.

\subsection{Apresentação das Anotações na Web}

A apresentação das anotações, bem como dos slides capturados durante uma sessão de aula é realizada pelo Sistema iClass (Seção 2.1). O iClass, similar em funcionalidade ao eClass, foi desenvolvido no ICMC-USP e permite a captura de diferentes fluxos de informação (slides e anotações sobre os mesmos, áudio e vídeo) durante uma aula convencional realizada em ambientes de sala de aula instrumentada. O iClass segue quatro fases que representam uma possível estruturação do problema de captura e acesso [Abowd, 1999]:

1. Pré-produção: consiste na preparação de materiais para a sessão de captura. Também são adicionadas informações contextuais, como a que curso uma aula deve ser associada. Uma série de páginas JSP ${ }^{\varangle}$ são usadas para a criação de aulas, possibilitando que o professor carrcgue slides pré-preparados (imagens JPEG ou PNG) para cadáa aula e reuse matcriais previamente capturados cm outras aulas [Sante, 2003] ${ }^{9}$;

2. Gravação ao vivo: sincronização e captura dos fluxos de informação relevantes. Nessa fase é feito uso de um applet responsável por instanciar os componentes xINCA de captura (whiteboard, áudio, vídco e web logging) a sercm utilizados durante a aula;

3. Pós-produção: integração dos fluxos de informação capturados c geração de um documento XML representativo da sessão. Nessa fase o documento XML é processado por três folhas de estilo XSLT ${ }^{10}$, gerando documentos SMIL ${ }^{11}$, XHTML+SMIL ${ }^{12}$ e HTML. Os documentos SMIL e XHTML+SMIL possibilitam a apresentação multimídia da sessão, enquanto que o documento HTML é especial para a impressão dos slides da aula.

\footnotetext{
${ }^{7} \mathrm{http:} / / \mathrm{xml}$.apache org/xindice

${ }^{8} \mathrm{http}: / /$ java.sun.com/products/jsp/

${ }^{9}$ Trabalho de mestrado desenvolvido no contexto do Projeto InCA-SERVE

${ }^{10} \mathrm{http}: / / \mathrm{www} . \mathrm{w} 3 . \mathrm{org} / \mathrm{TR} / \mathrm{xslt}$

${ }^{11} \mathrm{http}: / /$ www.w3.org/TR/smil20

${ }^{12} \mathrm{http} / /$ www.w3.org/TR/XHTMLplusSMIL
} 
4. Acesso posterior: visualização, pelos usuários-finais, das informações capturadas de acordo com uma estrutura hierárquica em que aulas estão presentes em cursos, que sào ministrados em semestres [Andrade. 2003]. Com os documentos gerados na fase anterior, a visualização de uma aula pode ser feita nos formatos HTML, SMIL e XHTML+SMIL.

De acordo com a última fase descrita, podemos visualizar as anotações feitas durante uma sessão relativamente ao curso c à aula em que clas foram capturadas. A Figura 4.12 representa uma anotação fcita no 1o. scmestre de 2004, no curso de Seminários Avançados cm Hipermídia e na aula entitulada "testeBilly".

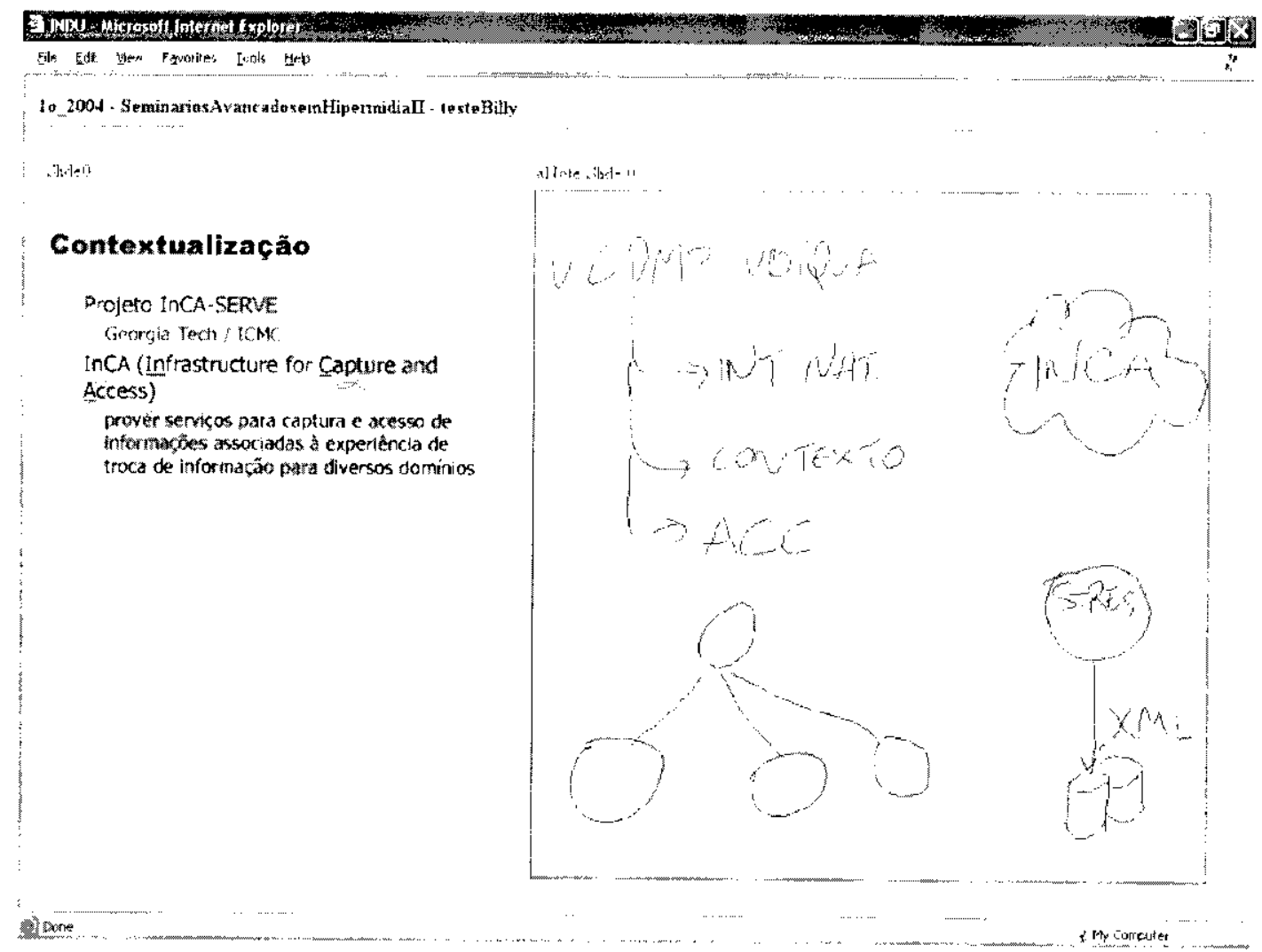

Figura 4.12: Visualização em IITML do uma anotação capturada.

A anotação exibida nessa figura representa aquela enviada pelo PDA da Figura 4.5 no momento em que o componente de whiteboard estava ilustrando o slide cujo título é "Contextualização". Também podcmos obscrvar a cxistência de anotações feitas sobre o slide da whiteboard. O documento HTML representado na Figura 4.12 foi gerado automaticamente 
a partir de uma folha de estilo XSLT e do documento X.ML de uma sessão armazenado no StRES.

\subsection{Considerações Finais}

A integração do sistema de anotaçós apresentado no decorrer deste capítulo com o Projeto InCA-SERVE permite a inclusão de PDAs em ambientes educacionais como uma ferramenta na qual os alunos produzem informaçōes privadas. No entanto, esse sistema ainda não foi aplicado cm um ambiente desse tipo, mas esperamos que a interação entre professores c alunos aumente na medida que esses alunos sintam a necessidade de expor suas idéias ou discutir sobre a resolução de um exercício através de suas próprias anotações, tornando-as públicas para a sala de aula.

Em relação aos aspectos de implementação, o Sistema aNOTE ainda pode ser estendido de forma a suportar operações mais sofisticadas sobre as anotações. Considerarnos que "copiar e colar" ou "arrastar e soltar" objetos, por exemplo, são operações convencionais amplamente realizadas no dia-a-dia e que poderiam ser implementadas no serviço iPocket. Além disso, o serviço iPublic também poderia agregar mais funcionalidades. Atualmente, qualquer stroke fcito sobre as mini-lousas do iPublic são instantaneamente enviados para o PDA do respectivo aluno. Talvez seja interessante que os strokes scjam enviados para todos alunos. Talve\% seja mais adequado que os strokes não sejam transmitidos instantaneamente, evitando possívcis problemas de consistência. Enfim, consideramos que o próximo passo é aplicar o sistcma em um ambiente real para podermos conhecer as necessidades e dificuldades dos usuários. Esse é um assunto que, inclusive, demanda a aplicação de um experimento controlado.

Todavia, nosso interesse foi descnvolver um sistema que fosse capaz de realizar, cm linhas gerais, comunicação entre dispositivos computacionais, armazenamento de informações e acesso às mesmas. A integração com o Projeto InCA-SERVE ocorreu devido ao cumprimento dessas etapas. Finalmente, no próximo capítulo apresentamos as conclusões finais, as contribuiçoes e os trabalhos futuros. 


\section{Capítulo 5}

\section{Conclusão}

\subsection{Considerações Iniciais}

Com este trabalho investigamos a possibilidade e a viabilidade de utilização de dispositivos móveis de modo integrado a ambientes que suportam a captura de informações públicas para posterior acesso a documentos associados. No contexto do Projeto InCA-SERVE, fornecemos um conjunto de serviços que trabalham de forma integrada, buscando apoiar atividades de anotações de usuários em ambientes educaacionais. Esses serviços permitem que usuários manipulem suas anotações, armazenando-as digitalmente seja em scu próprio PDA ou em um repositório Web. Ao suportar a existência de um ambiente colaborativo, juntamente com as outras aplicações do Projeto iClass, acreditamos que o sistema desenvolvido possa estimular, senão mesmo aumentar o envolvimento de alunos cm tarefas intra-classe promovidas pelo professor. Isso porque, na literatura são relatados alguns estudos que indican um maior aprendizado de alunos quando são utilizadas aplicações multimídia em salas de aula (por exemplo [Macaulay, 2003]).

A integração do Sistema aNOTE ao Projeto InCA-SERVE foi acompanhada por uma sćrie de cstudos relacionados à infra-estrutura de software INCA, às tecnologias de comunicação cntre PDAs c computadores convencionais, ao desenvolvimento de aplicações para dispositivos móvcis c ao esquema de armazenamento de documentos XML utilizado pelos serviços do StRES. Como resultado, o aNOTE foi construído como uma camada acima da INCA, 
utilizando seus módulos e interfaces para facilitar a troca de anotaçós através da rede. Além disso, estamos rcalizando a troca de informações através de redes sem fio como uma alternativa mais confiávol, mais rápida o mais transparente do que dispositivos receptores de infravermelho ou bases de sincronismo de PDAs.

Em relação a aplicações para dispositivos móveis, descnvolvemos um módulo mais abstrato para a manipulação da base de dados desses dispositivos e, também, projetamos uma área de entrada de dados (anotaçoes) que não é limitada ao tamanho físico da tela do dispositivo. Para a criação de anotações nessa árca, elaboramos um mecanismo de rolagem automática de textos e o avaliamos com um experimento aplicado a 14 usuários, cujos resultados foram satisfatórios. Além disso, também avaliamos a questão da orientação espacial na área de entrada de dados através do um experimento aplicado a 24 usuários c concluímos que eles conseguem diminuir o tempo de interação a cada nova tarefa sem altcrar a qualidado de sua orientação espacial.

Na questão do armazenamento, primeiramente estudamos como as informações são processadas pelas entidades do StRES e como são realizados os mecanismos de criação de objetos Java a partir de documentos de definição de dados (DTDs) e a conversão desses objetos em um documento XML que representa uma sessão de captura. A partir desse XML, podemos apresentar as anotações capturadas para o usuário-fimal, juntamente com os slides relacionados, utilizando documentos HTML, SMIL ou XHTML+SMIL.

\subsection{Resultados e Contribuições}

Em relação aos principais resultados e contribuições deste trabalho, podemos citar:

- Integração de PI)As ao Projeto InCA-SERVE, utilizando as infra-estruturas de software INCA e StRES e o Projeto iClass, que está cm operação no ICMC desde Agosto de 2002, com mais de 150 aulas capturadas entre cursos de graduação c pós-graduação;

- Descnvolvimento de um módulo que abstrai a comunicação entro aplicaçócs c a baso do dados de PDAs;

- Construção de uma ferramenta para permitir a realização de anotações crn uma área 
que extrapola os limites da tela de PDAs;

- Elaboração de um mecanismo de rolagem automática de textos como parte da ferramenta citada anteriormente:

- Condução de um cxperimento para avaliar o tempo e a precisão de um usuário ao utilizar o mecanismo citado no item antcrior;

- Avaliação do impacto causado pela utilização de uma área de escrita virtual que extrapola o tamanho da tola dos PDAs através dá aplicação de um experimento controlado;

- Submissão de um artigo à revista Interfaces do British HCI Group para relatar os resultados satisfatórios do expcrimento da rolagem automática de textos.

\subsection{Trabalhos Futuros}

Em relação aos trabalhos que podem ser realizados de modo a explorar os resultados já obtidos, existe um mostrado em andamento, no contexto do Projeto InCA-SERVE, que trata do reconhecimento de voz, gcstos e escrita [Inacio Jr., 2003]. A integração com este trabalho permitiria que as anotações do Sistema aNOTE fossem reconhecidas como textos, e não como imagens, o que favoreceria processos de busca nas anotações. O reconhecimento de voz também poderia ser utilizado para suportar operações em PDAs como "criar slide" ou "enviar anotação" de forma que a interação do usuário fosse a mais natural possível.

Entre os trabalhos que podem ser realizados como extensão deste, citamos:

- Troca de anotações entre PDAs para favorecer a colaboração direta entre alunos em uma sala de aula;

- Adição de informações de contexto de tal forma que o curso e a aula sejam automaticamente configurados, dependendo do ambiente em que o aluno se encontra;

- Transferência da relarãa de cursos e aulas de um determinado semestre para os PDAs dos alunos; 
- Sincronização das anotações do PDA com um PC de forma que as anotaçõos privadas de um aluno também possam ser visualizadas na WEB;

- Criação de um modelo capaz de permitir que anotações sejam enviadas para um repositório público mesmo após o término de uma sessão.

Por fim, ressaltamos a importância da aplicação de um experimento que cnvolvesse todo o Sistema aNOTE de forma que pudéssemos responder a questões do tipo: "Qual a frequência que alunos realizam anotações em um ambiente onde as informações do professor já estão sendo capturadas?". ou ainda "Os alunos sentem-se motivados a tormar públicas suas anotações em uma sala de aula?". 


\section{Referências Bibliográficas}

[Abowd, 1999] Abowd, G. D. (1999). Software engineering issues for ubiquitous computing. Em Proceedings of the 21st International Conference on Software Engineering, páginas 75-84, Los Angeles. California, United States. IEEE Computer Society Press.

[Abowd et al., 1998a] Abowd, G. D., Atkeson, C. G., Brotherton, J., Enqvist, T., Gulley, P., c LcMon, J. (1998a). Investigating the capture, integration and access problem of ubiquitous computing in an educational setting. Em Conference Proceedings on Human Factors in Computing Systems, páginas 440-447, Los Angeles, California, United States. ACM Press/Addison-Wesley Publishing Co.

[Abowd et al., 1998b] Abowd, G. D., Brotherton, J., e Bhalodia, J. (1998b). Classroom 2000: a system for capturing and accessing multimedia classroom cxperiences. Em Proceedings of the Conference on CHI summary: Human Factors in Computing Systems, páginas 20 21, Los Angeles, California, Lnited States. ACM Press.

[Abowd e Mynatt, 2000] Abowd, G. D. c Mynatt, E. D. (2000). Charting past, present, and future research in ubiquitous computing. ACM Transactions on Computer-Human Interacion, $7(1): 29.58$.

[Andrade, 2003] Andrade, A. (2003). Visualização e apresentação de sessões capturadas cm ambientes de computação ubíqua. Monografia de Qualificação de Mestrado ICMC-USP.

[Baldochi et al., 2003] Baldochi, L., Cattelan, R., e Pimentel, M. (2003). Building a middleware infrastructure for capture and access applications. Em Anais do XXX Seminário Integrado de Software e Hardware - SBC, páginas 299-313. 
[Beigl, 2000] Beigl, M. (2000). Memoclip: A location-based remembrance appliance. Personal Ubiquilous Computing, 4(4):230-233.

[Beigl et al., 2002] Beigl, M., Zimmer, T., e Decker, C. (2002). A location model for communicating and processing of context. Personal Ubiquilous Computing, 6(5-6):341-357.

[Bellotti et al., 2003] Bellotti, F., Berta, R., De Gloria, A., Ferretti, E., e Margarone, M. (2003). Vegame: Exploring art and history in venice. Computer, 36(9):48-55.

[Braunberger, 2001] Braunberger, P. (2001). The clock-drawing test. http://199.243.225.113/ClinicalAssistant/scales/clock_drawing_test.htm, acesso em Fevereiro de 2004.

[Brotherton e Abowd, 1998] Brotherton, J.e Abowd, G. D. (1998). Rooms take note: Room take notes! Em Working Papers of AAAI Spring Symposium.

[Brotherton et al., 1998] Brotherton, J., Bhalodia, J., c Abowd, G. D. (1998). Automaled capturc, integration and visualization of multiple media streams. Em Proceedings of IEEE Multimedia, páginas 54-63.

[Buchanan et al., 2001] Buchanan, G., Farrant, S., Jones, M., Thimbleby, H., Marsden, G., e Pazzani, M. (2001). Improving mobile internet usability. Em Proceedings of the Tenth International Conference on World Wide Web, páginas 673-680. ACM Press.

[Cattclan et al., 2003] Cattclan, R., Andrade, A., Rocha, C., e Pimentel, M. (2003). iclass: um sistema para captura e acesso de sessões em ambicnte educacional. Revista Eletrônica de Iniciaçào Chentifica da $S B C, 3(1): 10-28$.

[Covington et al., 2001] Covington, M. J., Long, W., Srinivasan, S., Dev, A. K., Ahamad, M., e Abowd, G. D. (2001). Securing context-aware applications using environment roles. Em Proceedings of the Sixh ACM Symposium on Access conlrol models e technologies. páginas 10-20. ACM Press.

[Davis ct al., 1999] Davis, R. C., Landay, J. A., Chen, V., Huang, J., Lee, R. B., Li, F. C., Lin, J., Charles B. Morrey, I., Schleimer. B., Price, M. N., e Schilit, B. N. (1999). Notepals: 
lightweight note sharing by the group, for the group. Em Proceeding of the CHI Conference on Human Factors in Computing Systems: the CHI is the limit, páginas 338-345, Pittsburgh, Pennsylvania. United States. ACM Press.

[Dey, 2001] Dey, A. K. (2001). Understanding and using context. Personal Ubiquitous Computing, 5(1):4.7.

[Dey et al., 1999] Dey, A. K., Salber, D., Abowd, G. D., e Futakawa, M. (1999). The conference assistant: Combining context-awareness with wearable computing. Em Proceedings of the 3rd IEEE International Symposium on Wearable Computers, página 21. IEEE Computer Society.

[Flippo, 2003] Flippo, F. (2003). A natural human-computer interface for controlling wheeled robotic vehicles. Disscrtação de Mestrado, Rutgers University, Piscataway, New Jersey, LSA. www.caip.rutgers.edu/fflippo/docs/llippo/thesis.pdf, acesso em Feverciro de 2004 .

[Greenberg ot al., 1999] Greenberg, S., Boyle, M., e Laberg, J. (1999). Pdas c shared public displays: Making personal information public, e public information personal. Personal Technologies, 3(1):54-64.

[Hazan, 2003] Hazan, G. C. (2003). Superwaba input output tutorial. Tutorial obtido no site: http://www.superwaba.com.br em Novembro de 2003.

[Heiner et al., 1999] Heiner, J. M., Hudson, S. E., e Tanaka, K. (1999). The information percolator: ambient information display in a decorative object. Em Proceedings of the 12th Annual ACM Symposium on User Interface Software e Technology, páginas 141-148. ACM Press.

[Higel et al., 2003] Higel, S., O'Donnell, T., e Wade, V. (2003). Towards a natural interface to adaptive scrvice composition. Em Proceedings of the 1st International Symposium on Information e communicalion technologies, páginas 169-174. Trinity College Dublin.

[Inacio Jr., 2003] Inacio Jr., V. R. (2003). Componentes para armazenamento e intercâmbio de informações em ambientes de computação ubíqua. Relatório ICMC-USP. 
[iPAQ, 2003] iPAQ. H. (2003). Hp ipaq pocket pe h5500 series summary. http://welcome.hp.com/country/us/en/prodserv/heheld.html, acesso em Fevereiro de 2004 .

[Jones et al., 2003] Jones, M., Buchanan, G., e Thimbleby, H. (2003). Improving web scarch on small screen devices. Interacting with Computers, 15:479-495.

[Kidd et al., 1999] Kidd, C. D., Orr, R., Abowd. G. D., Atkeson, C. G., Essa, I. A., MacIntyre, B., Mynatt, E. D., Starner, T., e Newstetter, W. (1999). The aware home: A living laboratory for ubiquitous computing research. Em Cooperative Buildings, páginas 191198.

[Macaulay, 2003] Macaulay, M. (2003). The effects of multimedia on learning in third world children. Journal of Educational Multimedia e Hypermedia, 12(2):185-198.

[Masicro ct ał., 2003] Masiero, P., Moreira, E., c Pimentel, M. (2003). Using iclass towards applied mobile technology solutions in learning environments. Proposta aprovada: HP Company 2003 Grant Initiative Request for Proposal-Latin America.

[Muñoz et al., 2003] Muñoz, M. A., Rodríguez, M., Favela, J., Martincz-Garcia, A. I., e González, V. M. (2003). Context-aware mobile communication in hospitals. Computer, $36(9): 38 \quad 46$.

[Mynatt et al., 2001] Mynatt, E. D., Rowan, J., Craighill, S., e Jacobs, A. (2001). Digital family portraits: supporting peace of mind for extended family members. Em Proceedings of the SIGCHI Conference on Human Faclors in Computing Systems, páginas 333 340. ACM Press.

[Nagel et al., 2001] Nagel, K., Kidd, C. D., O'Connell, 'T., Dey, A. K., e Abowd, G. D. (2001). The family intercom: Developing a context-aware audio communication system. Em Proceedings of the 3rd International Conference on Ubiquitous Computing, páginas 176-183. Springer-Verlag.

[Nakanishi ct, al., 2002] Nakanishi, Y., Sato. Y., e Koike, H. (2002). Enhancoddesk and enhancedwall: Augmented desk and wall interfaces with real-time tracking of user's motion. 
Em Ubicomp - Workshop on Collaborations with Interactive Walls and Tables, páginas 2730 .

[Nielsen, 1996] Nielsen, J. (1996). T'op ten mistakes in web dosign. http://www.useit.com/alertbox/9605.html, acesso em Fevereiro de 2004.

[Öquist e Goldstein, 2003] Öquist, G. e Goldstein. M. (2003). Towards an improved readability on mobile devices: evaluating adaptive rapid serial visual presentation. Interacting with Computers, 15:539-558.

[Pimentel et al., 2000] Pimentel, M., Abowd, G., e Ishiguro, Y. (2000). Linking by interacting: a paradigm for authoring hypertext. Em Proceedings of the ACM Conference on Hypertext and Hypermedia, páginas 39-48.

[Pimentel e Abowd, 1999] Pimentel, M. G. C. e Abowd, G. D. (1999). Development and understanding of automated capture enviroments to support long-term use. Projeto de Cooperação Intcrnacional aprovado junto ao ProToM-Ce-Cnpq/Brasil e ao NSF-EUA.

[Salber et al., 1999] Salber, D., Dey, A. K., c Abowd, G. D. (1999). The context toolkit: aiding the development of context-enabled applications. Em Proceedings of the SIGCHI Conference on Human Factors in Computing Systems, páginas 434-441. ACM Press.

[Sante, 2003] Sante, D. (2003). Autore: suportando antoria evolucionária em ambicntes de captura. Dissertação de Mestrado do ICMC-USP.

[Tatar et al., 2003] Tatar, D., Roschelle, J., Vahey, P., c Penuel, W. R. (2003). Handhelds go to school: Lessons learned. Computer, 36(9):30-37.

[Truong e Abowd, 2004] Truong, K. e Abowd, G. (2004). Inca: A software infrastructure to facilitate the construction and evolution of ubiquitous capture \& access applications. Em Proceedings of the 2004 Inlernational Conference on Pervasive Computing. To appear.

[Truong et al., 2001] Truong, K., Abowd, G., e Brotherton, J. (2001). Who, what, when, where, how: Design issues of capture \& access applications. Em Proceedings of the Ubicomp, páginas 209-224. 
[Watters et al., 2003] Watters, C., Duffy, J., e Duffy, K. (2003). Using large tables on small display devices. Int. J. Human-Computer Studies, 58:21-37.

[Waycott e Kukulska-Hulme, 2003] Waycott, J. e Kukulska-Hulme, A. (2003). Students' experiences with pdas for reading course materials. Personal Ubiquitous Computing, 7(1):3043.

[Weiser, 1993] Weiser, M. (1993). Some computer science issues in ubiquitous computing. Communications of the ACM, 7(6):75-84.

[Weiser, 2004] Weiser, M. (2004). Ubiquitous computing. http://www.ubiq.com/hypcrtext/weiser/UbiHome.html.

[Ycc, 2003] Ycc, K. (2003). Peephole displays: pen interaction on spatially aware handhcld computers. Em Proceedings of the Conference on Human Factors in Computing Systems, páginas 1. 8. ACM Press. 